\title{
MEASURED THERMAL AND FAST NEUTRON FLUENCE RATES ATR CYCLES 165A
}

Billy J Walker, Michael A Reichenberger

September 2019

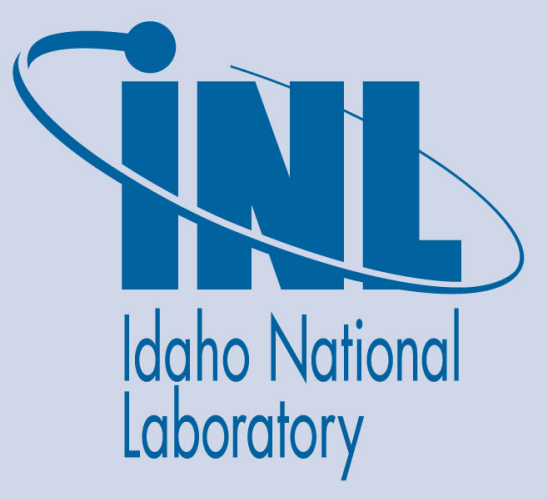

The INL is a U.S. Department of Energy National Laboratory operated by Battelle Energy Alliance 


\title{
MEASURED THERMAL AND FAST NEUTRON FLUENCE RATES ATR CYCLES 165A
}

\author{
Billy J Walker, Michael A Reichenberger
}

September 2019

Idaho National Laboratory Idaho Falls, Idaho 83415

http://www.inl.gov

Prepared for the

U.S. Department of Energy

Under DOE Idaho Operations Office

Contract DE-AC07-05ID14517 


\section{INL/EXT-19-55526}

MEASURED THERMAL AND

FAST NEUTRON FLUENCE

RATES ATR CYCLES 165A

Revision 0

1/18/19 thru 6/19/19

B. J. Walker and M. A. Reichenberger

September, 2019 


\section{MEASURED THERMAL AND FAST NEUTRON FLUENCE RATES \\ ATR CYCLE 165A \\ Revision 0 \\ $1 / 18 / 19$ thru $6 / 19 / 19$}

B. J. Walker and M. A. Reichenberger

This report contains the thermal $(2200 \mathrm{~m} / \mathrm{s})$ and fast $(\mathrm{E}>1 \mathrm{MeV})$ neutron fluence rate data for ATR Cycle 165A which were measured by the Radiation Measurements Laboratory (RML) as requested by the Power Reactor Programs (ATR Experiments) Radiation Measurements Work Order.

This report contains fluence rate values corresponding to the particular elevations (relative to the $80-\mathrm{ft}$. core elevation) where the measurements were taken. The data in this report consists of (1) a table of the ATR power history and distribution, (2) a hard copy listing of all thermal and fast neutron fluence rates, (3) plots of both the thermal and fast neutron fluence rates, and (4) an optical record (compact disk) containing a listing of the thermal and the fast neutron fluence rates, their assigned elevations and proper header identification of all monitor positions contained herein.

The fluence rates reported are for the average power levels given in the table of power history and distribution.

No neutron monitors were located in the $\mathrm{N}-2$ position during this cycle.

All "SR" holder monitor wires for this cycle are 55 inches long. This length allows measurements from 24.73 inches above core midplane to 25.25 inches below core midplane. The distance from the end of the wires to the first count position was 4.25 inches for all wires counted from this cycle.

During the irradiation of Cycle 152A, the RML performed additional flux measurements to assess core reconfiguration issues. Measurements using cadmium covered as well as bare neutron monitors in the Southwest, Southeast, and H positions of the Center lobe were performed to determine the division in neutron energy between epithermal and thermal neutrons. This is defined as the resonance correction defined in this report. It is used to quantify both thermal and fast neutron flux. For more information please refer to letter, "RADIATION MEASUREMENTS LABORATORY MEASUREMENTS OF IN CORE ATR PHYSICS TESTING DURING CYCLE 152A" dated January 24, 2013, to Casey Stengel from C. C. Jensen. The measured values documented in RML Procedure, "ACMM-3600, Flux Monitoring," will be used indefinitely until further measurements supersede the current values. 


\section{DEFINITIONS OF REPORTED INFORMATION}

\section{ON PRINTED PAGES}

1. CYCLE: The identification code given to a specific period of operation of the ATR for which the data in this report applies.

2. POSITION: The identification code given to a specific location in the ATR core area where neutron monitors were located and for which the data associated with the code apply. The letter code identifies the lobe and the number code identifies a monitor position.

3. MONITOR ID: The identification code given to a specific neutron monitor holder. The code is stamped on the holder. The letter code identifies the type of holder and the number is unique to allow tracking of the neutron monitors and their data.

4. EFPD: The acronym for, "Effective Full Power Days" which is the effective number of days the ATR operated at the average total core power level of the cycle. This value is obtained from the ATR power history and distribution.

5. AVERAGE MW: The average power level (in megawatts) at which the ATR lobe operated during the cycle. The values used for NW, NE, C, SW, and SE lobes are obtained from the ATR power history and distribution. The values used for the other lobes and core positions are determined as follows:

$$
\begin{aligned}
& \mathrm{N}=(\mathrm{NE}+\mathrm{NW}+\mathrm{C}) / 3 \\
& \mathrm{E}=(\mathrm{NE}+\mathrm{SE}+\mathrm{C}) / 3 \\
& \mathrm{~S}=(\mathrm{SE}+\mathrm{SW}+\mathrm{C}) / 3 \\
& \mathrm{~W}=(\mathrm{NW}+\mathrm{SW}+\mathrm{C}) / 3
\end{aligned}
$$

$$
\begin{aligned}
\text { A1 through } \quad \mathrm{A} 8 & =\mathrm{C} \\
\mathrm{A} 9 & =\mathrm{NE} \\
\mathrm{A} 10 & =\mathrm{SE} \\
\mathrm{A} 11 & =\mathrm{SW} \\
\mathrm{A} 12 & =\mathrm{NW}
\end{aligned}
$$
$\mathrm{B} 1$ or $\mathrm{B} 2=\mathrm{NE}$
$\mathrm{I} 21=\mathrm{NE}$
$\mathrm{B} 9=\mathrm{N}$
$\mathrm{B} 3$ or $\mathrm{B} 4=\mathrm{SE}$
$\mathrm{I} 22=\mathrm{SE}$
$\mathrm{B} 10=\mathrm{E}$
$\mathrm{B} 5$ or $\mathrm{B} 6=\mathrm{SW}$
$\mathrm{I} 23=\mathrm{SW}$
$\mathrm{B} 11=\mathrm{S}$
$\mathrm{B} 7$ or $\mathrm{B} 8=\mathrm{NW}$
$\mathrm{I} 24=\mathrm{NW}$
$\mathrm{B} 12=\mathrm{W}$

6. DATE: The calendar dates corresponding to the outage and operating time of the cycle. These dates include the forced outage time associated with the cycle as well as the operating time. 
7. ELEVATION: The vertical position associated with the neutron fluence rate measurement value relative to the $80 \mathrm{ft}$. elevation of the ATR core. The elevation values are in inches and negative values are below the $80 \mathrm{ft}$. elevation (commonly referred to as centerline). The elevation values are established reference elevation points specified as follows:

\begin{tabular}{lcc} 
Holder Type & Reference Elevation & Drawing Numbers \\
\cline { 1 - 2 } $\mathrm{H}$ & $77.948 \mathrm{ft}$ & \\
$\mathrm{SR}$ & $77.768 \mathrm{ft}$ & 424852 \\
EPRI & $83.260 \mathrm{ft}$. & 417424 \\
AGR-3/4 & $77.906 \mathrm{ft}$ & 601418
\end{tabular}

Using the dimensions of the monitor holders, the location of the monitor wire in the holder, the length of the wire and the distance between the measurements along the wire an elevation value for each fluence rate value is determined. An evaluation of the elevation tolerances is listed as follows:

Holder Fabrication

Cutting the Monitor Wire to Length

Wire Alignment in the Holder

Mounting the Wire to the Scanner

Scanning Control

Scanner Home Positioning

Stackup of the Safety Rod

Components (estimated)

Position of the Safety Rod Relative

to $80 \mathrm{ft}$. (core centerline)

during Operation

95\% Confidence Bound

Maximum Error
SR

\begin{tabular}{|c|c|}
\hline Holders & Holders \\
\hline \pm 0.11 inch & \pm 0.11 inch \\
\hline $\pm 0.10 \mathrm{inch}$ & $\pm 0.10 \mathrm{inch}$ \\
\hline $\pm 0.13 \mathrm{inch}$ & $\pm 0.06 \mathrm{inch}$ \\
\hline $\pm 0.13 \mathrm{inch}$ & $\pm 0.13 \mathrm{inch}$ \\
\hline \pm 0.01 inch & $\pm 0.01 \mathrm{inch}$ \\
\hline $\pm 0.06 \mathrm{inch}$ & \pm 0.06 inch \\
\hline \pm 0.33 inch $^{*}$ & \\
\hline \pm 0.75 inch $^{* *}$ & \\
\hline $\pm 0.78 \mathrm{inch}$ & $\pm 0.19 \mathrm{inch}$ \\
\hline $\pm 1.53 \mathrm{inch}$ & $\pm 0.38 \mathrm{inc}$ \\
\hline
\end{tabular}

These elevation tolerances include only what are considered to be random errors.

Systematic

errors or biases may also occur due to information input. However, procedural controls are used to minimize this information input error.

*This estimate will be revised after an actual measurement is made.

**This estimate does not include variations due to thermal and hydraulic effects. 
8. "THERMAL": The equivalent $2200 \mathrm{~m} / \mathrm{s}(0.025 \mathrm{eV})$ neutron fluence rate assuming a Maxwellian distribution for the thermalized neutrons at $20.44 \mathrm{C}$. The fluence rate is determined from the Co-59 (n, $\gamma)$ Co-60 reaction rate assuming a 37 barn $2200 \mathrm{~m} / \mathrm{s}$ cross section for the reaction. Corrections for the epithermal reaction rate are made based on cadmium ratio measurements at each position of the fluence rate measurement. All fluence rate values are in units of neutrons per sqcm per second.

9. "FAST": The equivalent $>1 \mathrm{MeV}$ fission neutron energy fluence rate assuming a pure U-235 fission spectrum neutron energy distribution. The fluence rate is determined from the $\mathrm{Ni}-58(\mathrm{n}, \mathrm{p}) \mathrm{Co}-58$ reaction rate assuming a 0.092 barn fission spectrum averaged cross section for the reaction and a fission spectrum fraction of 0.692 for $>1 \mathrm{MeV}$ neutrons. Corrections for the burnout of the Co-58 isomers are made based on the measured 2200 $\mathrm{m} / \mathrm{s}$ fluence rate, the exposure duration and the burnout cross sections of the isomers [1650 barns ( 71 days), $1.7 \mathrm{E}+5$ barns ( 9.1 hours)] at each position of the fluence rate measurement.

10. CENTERLINE FLU. RATE: The neutron fluence rate at the elevation assignment nearest to the ATR core centerline elevation (0.0).

11. AVG. MAX. FLU. RATE: The average of the highest three adjacent values.

12. MAX. FLU. RATE/MW (AVG.): The average maximum fluence rate divided by the average power level (MW) of the lobe or position.

13. K FACTOR: The conversion factor determined from the neutron monitor activity for converting the net count rate at each elevation to the absolute reaction product $\left({ }^{60} \mathrm{Co}\right.$ or $\left.{ }^{58} \mathrm{Co}\right)$ radioactivity per unit mass of the monitor material $(\mathrm{d} / \mathrm{s} / \mathrm{mg})$.

14. RESONANCE CORRECTION: The fractional correction factor used to correct the Co-59 (n, $\gamma)$ Co-60 reaction rate for the epithermal neutron response at the position where the neutron monitor was located during irradiation. This correction factor was determined from cobalt "cadmium ratio" measurements at the same spatial location for the monitor geometry and atom density.

15. C/L BURNOUT CORRECTION: The correction factor for the burnout (transmutation) of the reaction products (Co-60, Co-58, Co-58m) of the neutron monitors during the cycle irradiation at the centerline fluence rate elevation. The burnout correction factors for other elevation assignments will vary (nonlinearly) depending on the "thermal" neutron fluence rates and cycle durations.

16. BACKGROUND (counts/sec.): The wire scanner detector background environment counting rate at the time the neutron monitor wires were scanned. 
17. CHECK SOURCE (counts/sec.)

Date Hour: The wire scanner detector check source count rate on the day the neutron monitor wires were scanned. The check source is a radioactive $\left({ }^{60} \mathrm{Co}\right)$ cobalt-aluminum wire mounted in a fixture which reproducibly positions it over the detector collimator. This check source is used to test counting functions (gain and stability) of the scanner counting system. The count rate is corrected for background and decay corrected to $08 / 30 / 08,12: 00$.

\section{ON PLOTS}

18. REACTOR: Identification of the reactor with which the data are associated (normally ATR).

19. CYCLE POWER: The total megawatt days of power produced during the reactor cycle. This value is normally obtained from the ATR power history and distribution information supplied by PRP.

20. MATERIAL: The element name of the neutron monitor material. The "thermal" neutron monitor material is normally an alloy $(\mathrm{CoAl})$ of cobalt $(\mathrm{Co})$ and aluminum (Al) where the weight percent is given preceding the percent (\%) symbol.

21. EXPERIMENT: The identification code given to the experiment located in the loop. This information is provided by PRP. 
POWER HISTORY AND DISTRIBUTION

CYCLE 165A

$1 / 18 / 19$

To

$6 / 19 / 19$

\begin{tabular}{c|cccccc}
\hline \multicolumn{1}{c}{ NW } & NE & C & SW & SE & $\begin{array}{c}\text { TOTAL } \\
\text { MWD }\end{array}$ \\
MWD & 252.25 & 256.95 & 405.95 & 582.97 & 438.65 & 1936.77 \\
EFPD & 13.37 & & & & & \\
$\begin{array}{c}\text { MWD/44 }= \\
\text { EFF. TE. }\end{array}$ & 5.73 & 5.84 & 9.23 & 13.25 & 9.97 & \\
$\begin{array}{c}\text { EFF. TE. / EFPD } \\
\text { PF }\end{array}$ & .429 & .437 & .690 & .991 & .747 & \\
$\begin{array}{c}\text { MWD/EFPD }= \\
\text { AVG. POWER } \\
\text { (MW) }\end{array}$ & 18.87 & 19.22 & 30.36 & 43.60 & 32.80 & \\
$\begin{array}{c}\text { TOTAL } \\
\text { MWD/EFPD }=\end{array}$ \\
$\begin{array}{c}\text { AVERAGE FULL } \\
\text { POWER (MW) }\end{array}$
\end{tabular}

The following power history was used for fluence rate determinations

Days

0.327

4.866

0.451

0.187

0.201

0.199

2.001

96.50

0.286

0.185

10.28

62
Power (MW)

50
0
46.5
105
59
105
44.859
0
46.5
105
144.859
0

0.345

0

0.321

0.725

0.407

0.725

1.000

0

0.321

0.725

1.000

0 
ATR NEUTRON MONITOR RESULTS

\begin{tabular}{|c|c|c|c|}
\hline \multirow[t]{3}{*}{$\begin{array}{l}\text { CYCLE: } \\
\text { EFPD: }\end{array}$} & $\begin{array}{l}165 \mathrm{~A} \\
13.4\end{array}$ & $\begin{array}{l}\text { POSITION: } N-1 \\
\text { AVERAGE MW: } 22.8\end{array}$ & $\begin{array}{l}\text { MONITOR ID: SR-082 } \\
\text { DATE: } 01 / 18 / 19 \text { to } 06 / 19 / 19\end{array}$ \\
\hline & $\begin{array}{l}\text { ELEVATION } \\
\text { from core } \mathrm{CL} \\
\text { (inches) }\end{array}$ & $\begin{array}{c}\text { "THERMAL" } \\
2200 \mathrm{~m} / \mathrm{s} \mathrm{CO} \\
(\mathrm{n} / \mathrm{cm} * 2 / \mathrm{sec})\end{array}$ & $\begin{array}{c}\text { "FAST" } \\
>1 \mathrm{MeV} N \\
\left(\mathrm{n} / \mathrm{cm}^{*} \neq 2 / \mathrm{sec}\right)\end{array}$ \\
\hline & $\begin{array}{r}24.73 \\
22.75 \\
20.75 \\
18.75 \\
16.75 \\
14.75 \\
12.75 \\
10.75 \\
8.75 \\
6.75 \\
4.75 \\
2.75 \\
0.75 \\
-1.25 \\
-3.25 \\
-5.25 \\
-7.25 \\
-9.25 \\
-11.25 \\
-13.25 \\
-15.25 \\
-17.25 \\
-19.25 \\
-21.25 \\
-23.25 \\
-25.25\end{array}$ & $\begin{array}{l}8.39 \mathrm{E}+12 \\
1.49 \mathrm{E}+13 \\
3.92 \mathrm{E}+13 \\
7.96 \mathrm{E}+13 \\
1.09 \mathrm{E}+14 \\
1.28 \mathrm{E}+14 \\
1.43 \mathrm{E}+14 \\
1.54 \mathrm{E}+14 \\
1.62 \mathrm{E}+14 \\
1.67 \mathrm{E}+14 \\
1.71 \mathrm{E}+14 \\
1.76 \mathrm{E}+14 \\
1.78 \mathrm{E}+14 \\
1.76 \mathrm{E}+14 \\
1.76 \mathrm{E}+14 \\
1.71 \mathrm{E}+14 \\
1.69 \mathrm{E}+14 \\
1.64 \mathrm{E}+14 \\
1.56 \mathrm{E}+14 \\
1.49 \mathrm{E}+14 \\
1.38 \mathrm{E}+14 \\
1.18 \mathrm{E}+14 \\
1.02 \mathrm{E}+14 \\
8.23 \mathrm{E}+13 \\
6.62 \mathrm{E}+13 \\
5.19 \mathrm{E}+13\end{array}$ & $\begin{array}{l}1.39 \mathrm{E}+13 \\
2.43 \mathrm{E}+13 \\
3.49 \mathrm{E}+13 \\
4.46 \mathrm{E}+13 \\
5.53 \mathrm{E}+13 \\
6.09 \mathrm{E}+13 \\
6.67 \mathrm{E}+13 \\
6.95 \mathrm{E}+13 \\
7.33 \mathrm{E}+13 \\
7.39 \mathrm{E}+13 \\
7.63 \mathrm{E}+13 \\
7.53 \mathrm{E}+13 \\
7.52 \mathrm{E}+13 \\
7.96 \mathrm{E}+13 \\
7.74 \mathrm{E}+13 \\
7.50 \mathrm{E}+13 \\
7.47 \mathrm{E}+13 \\
7.38 \mathrm{E}+13 \\
7.17 \mathrm{E}+13 \\
6.80 \mathrm{E}+13 \\
6.16 \mathrm{E}+13 \\
5.67 \mathrm{E}+13 \\
4.75 \mathrm{E}+13 \\
3.80 \mathrm{E}+13 \\
2.68 \mathrm{E}+13 \\
1.45 \mathrm{E}+13\end{array}$ \\
\hline \multirow{2}{*}{\multicolumn{2}{|c|}{$\begin{array}{l}\text { CENTER LINE FLU. RATE } \\
\text { AVG. MAX. FLU. RATE } \\
\text { MAX. FLU. RATE/MW (AVG.) } \\
\text { K FACTOR } \\
\text { RESONANCE CORRECTION } \\
\text { C/L. BURNOUT CORRECTION } \\
\text { BACKGROUND (COUNTS/SEC.) } \\
\text { CHECK SOURCE (COUNTS/SEC.) } \\
08 / 07 / 1908: 45\end{array}$}} & $\begin{array}{l}1.78 \mathrm{E}+14 \\
1.77 \mathrm{E}+14 \\
7.75 \mathrm{E}+12 \\
297.52 \\
0.76 \\
1.000 \\
9.13\end{array}$ & $\begin{array}{l}7.52 \mathrm{E}+13 \\
7.74 \mathrm{E}+13 \\
3.39 \mathrm{E}+12 \\
2689.22 \\
\mathrm{NA} \\
1.417 \\
9.13\end{array}$ \\
\hline & & 335 & 3353. \\
\hline
\end{tabular}


ATR NEUTRON MONITOR RESULTS

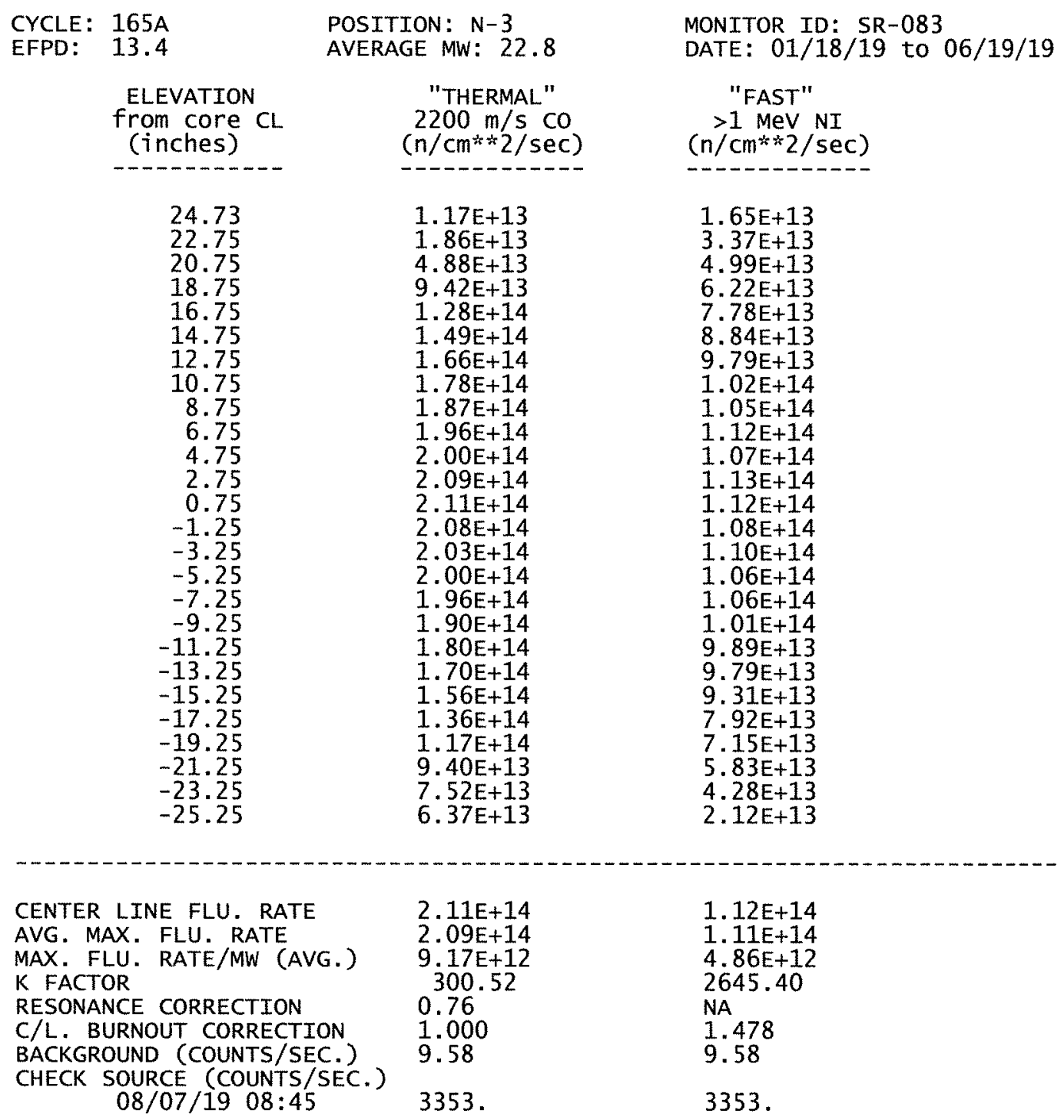


ATR NEUTRON MONITOR RESULTS

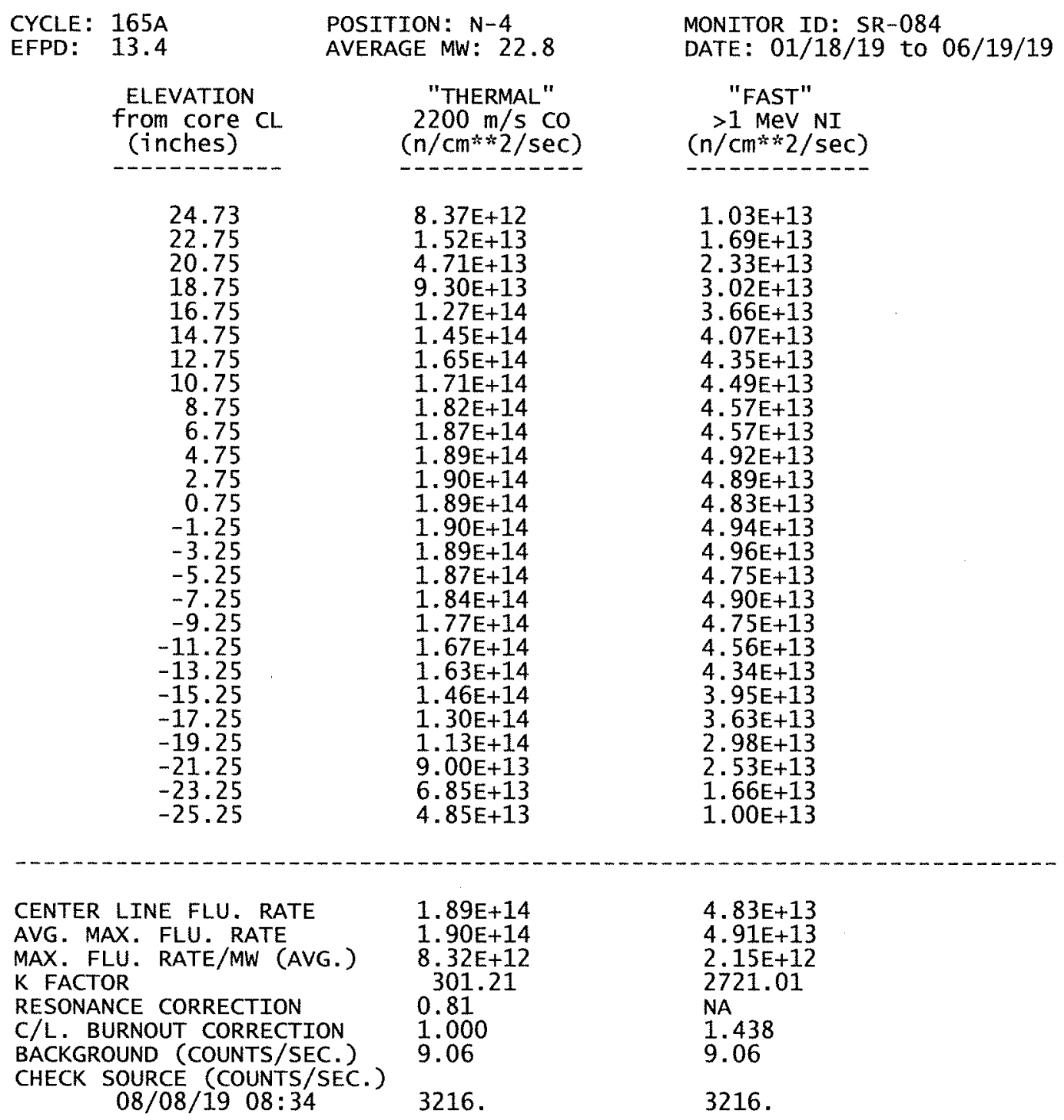


ATR NEUTRON MONITOR RESULTS

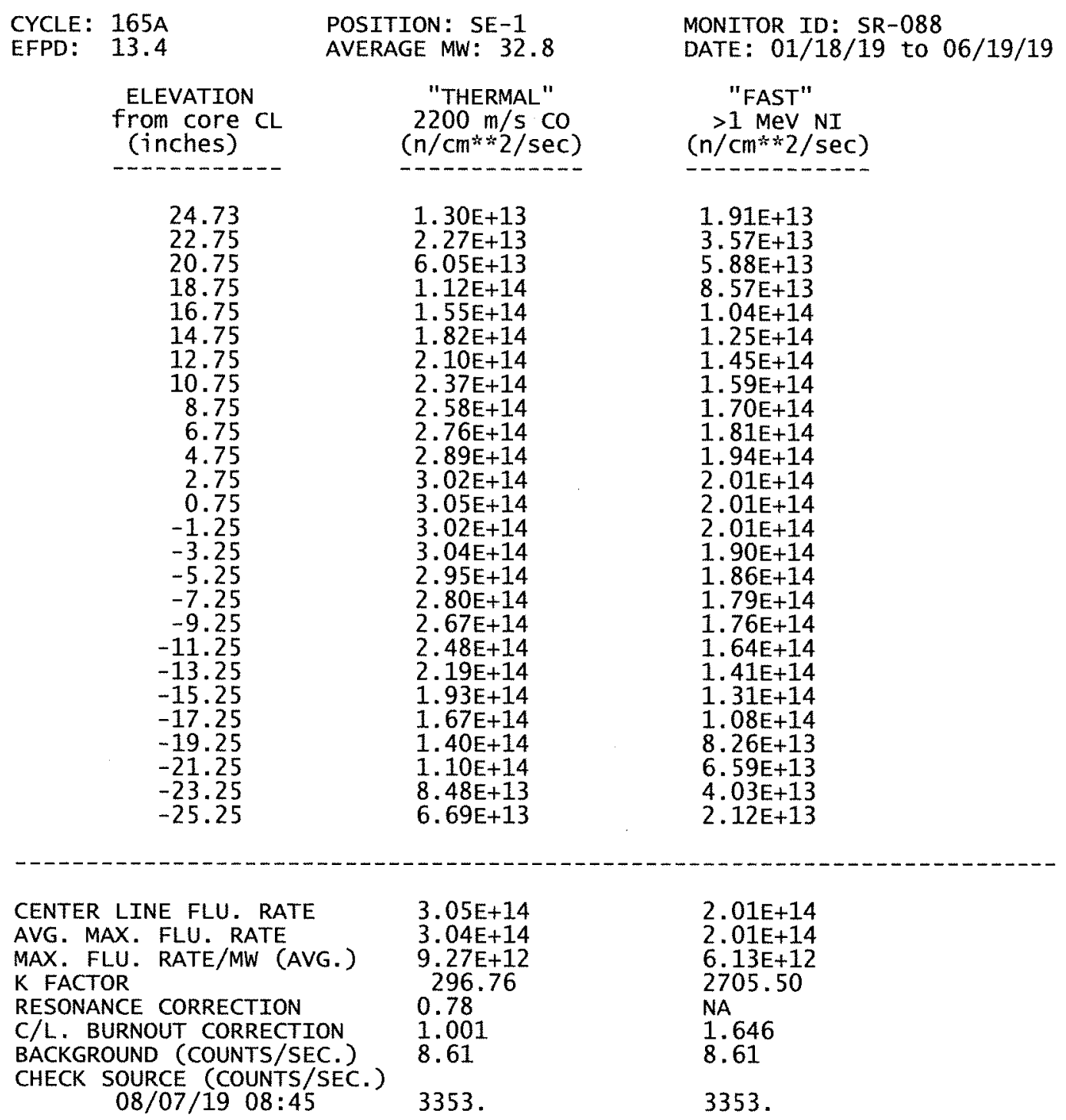


ATR NEUTRON MONITOR RESULTS

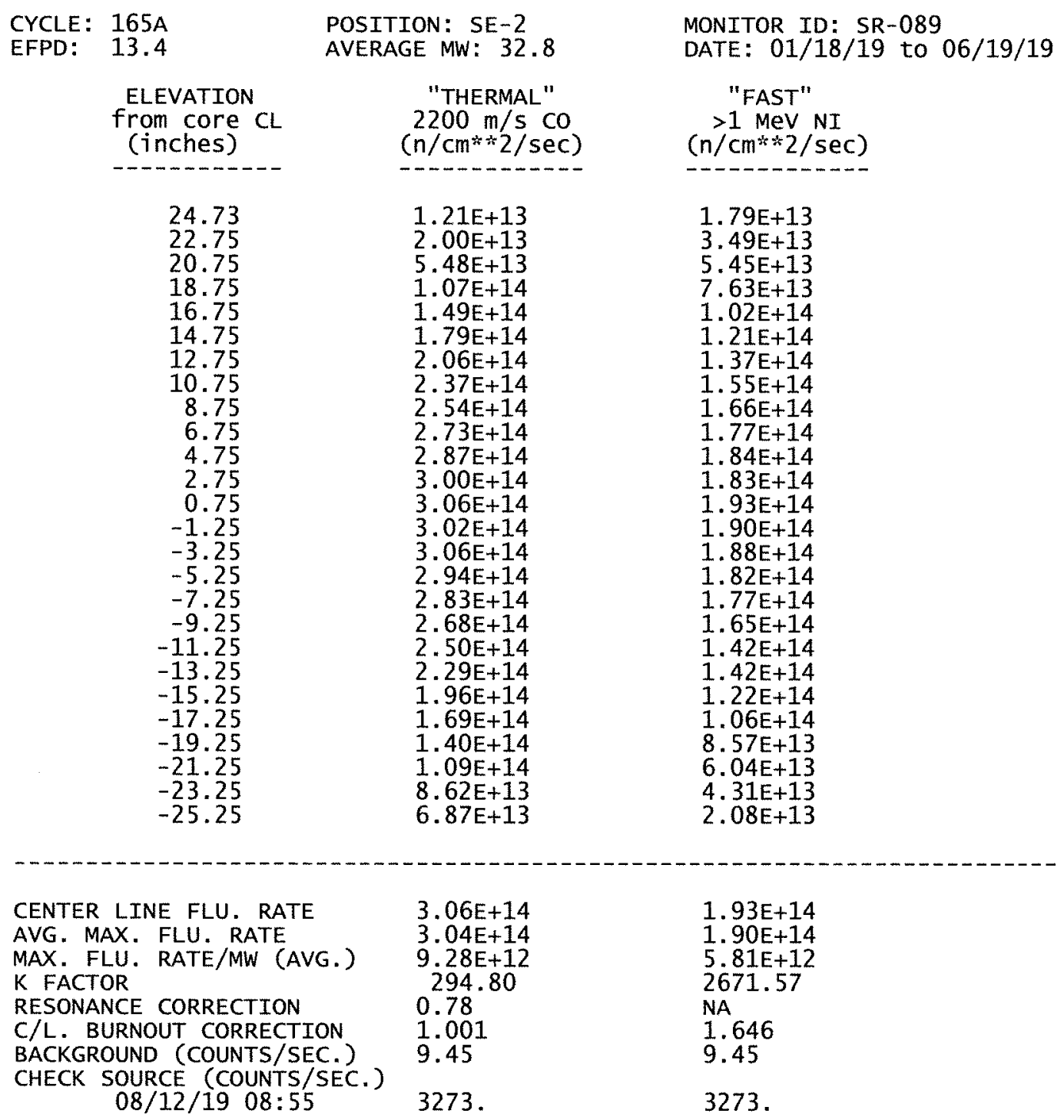


ATR NEUTRON MONITOR RESULTS

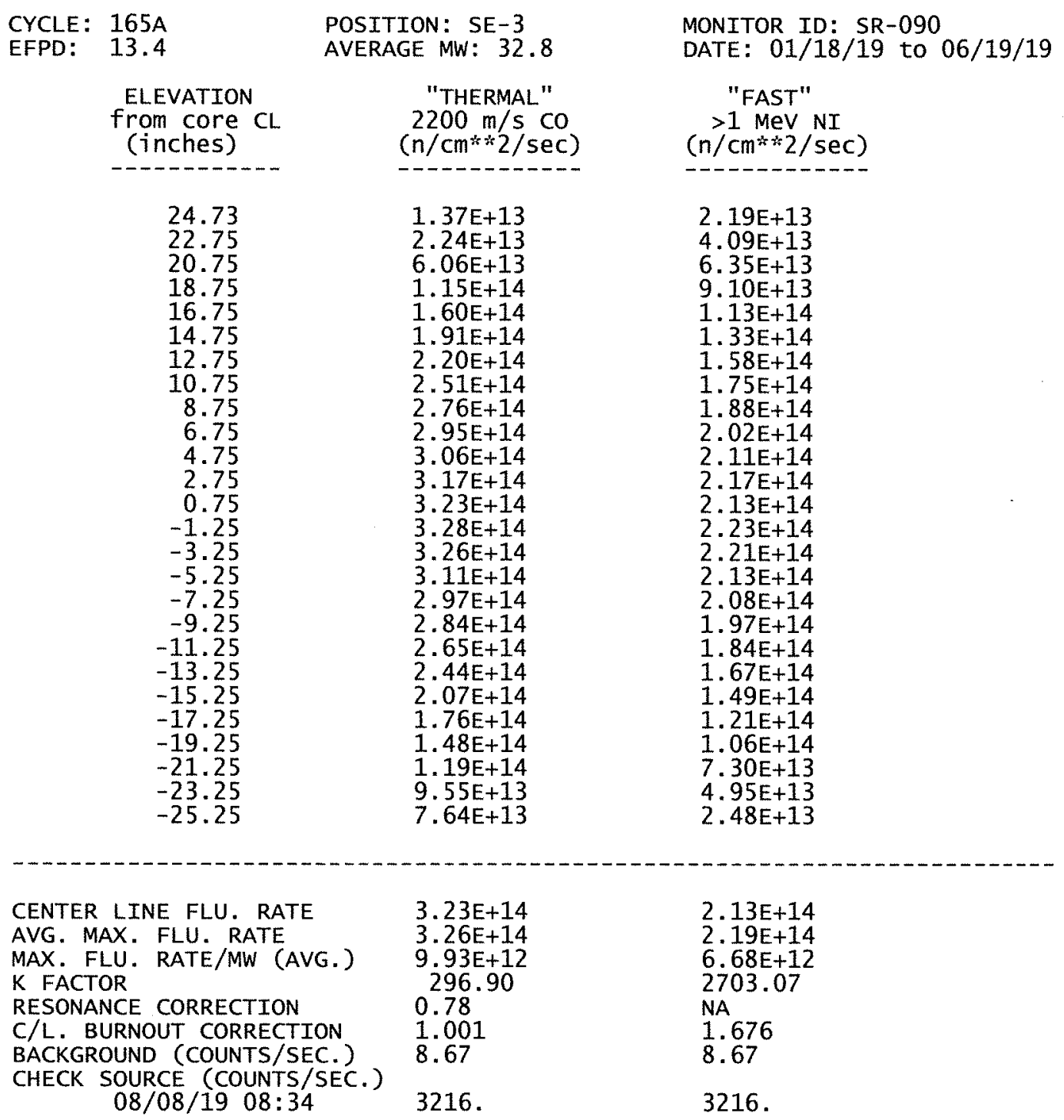


ATR NEUTRON MONITOR RESULTS

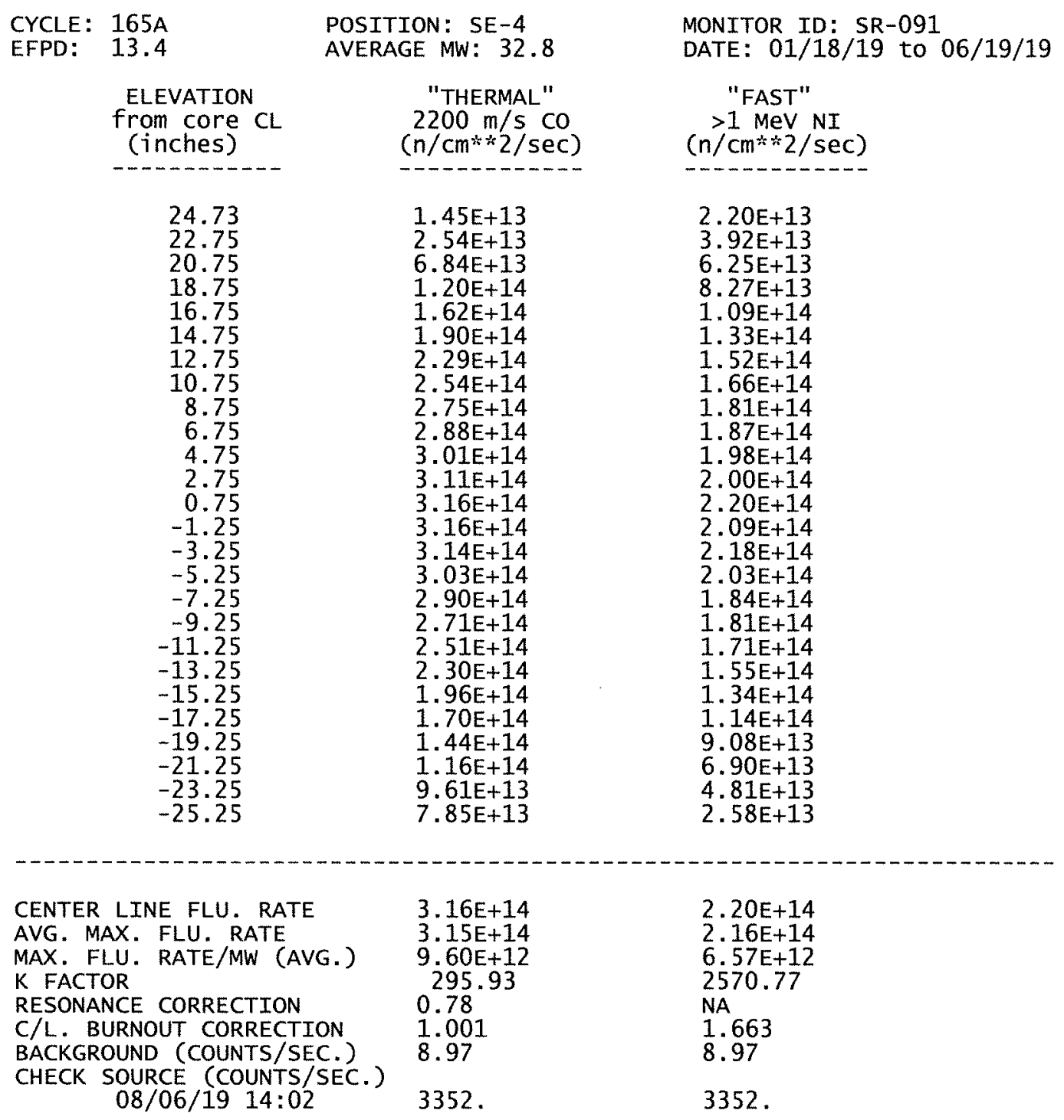


ATR NEUTRON MONITOR RESULTS

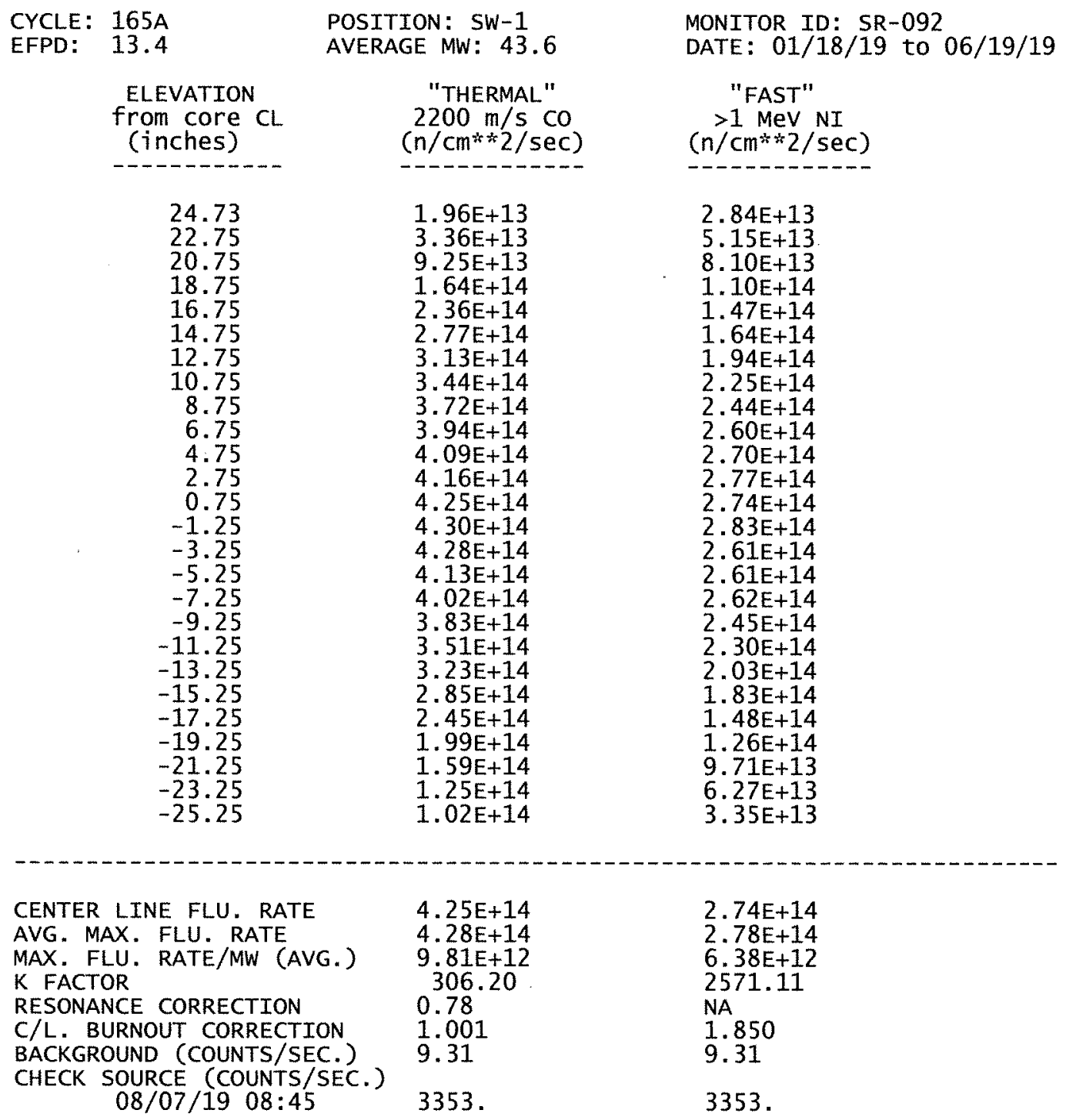


ATR NEUTRON MONITOR RESULTS

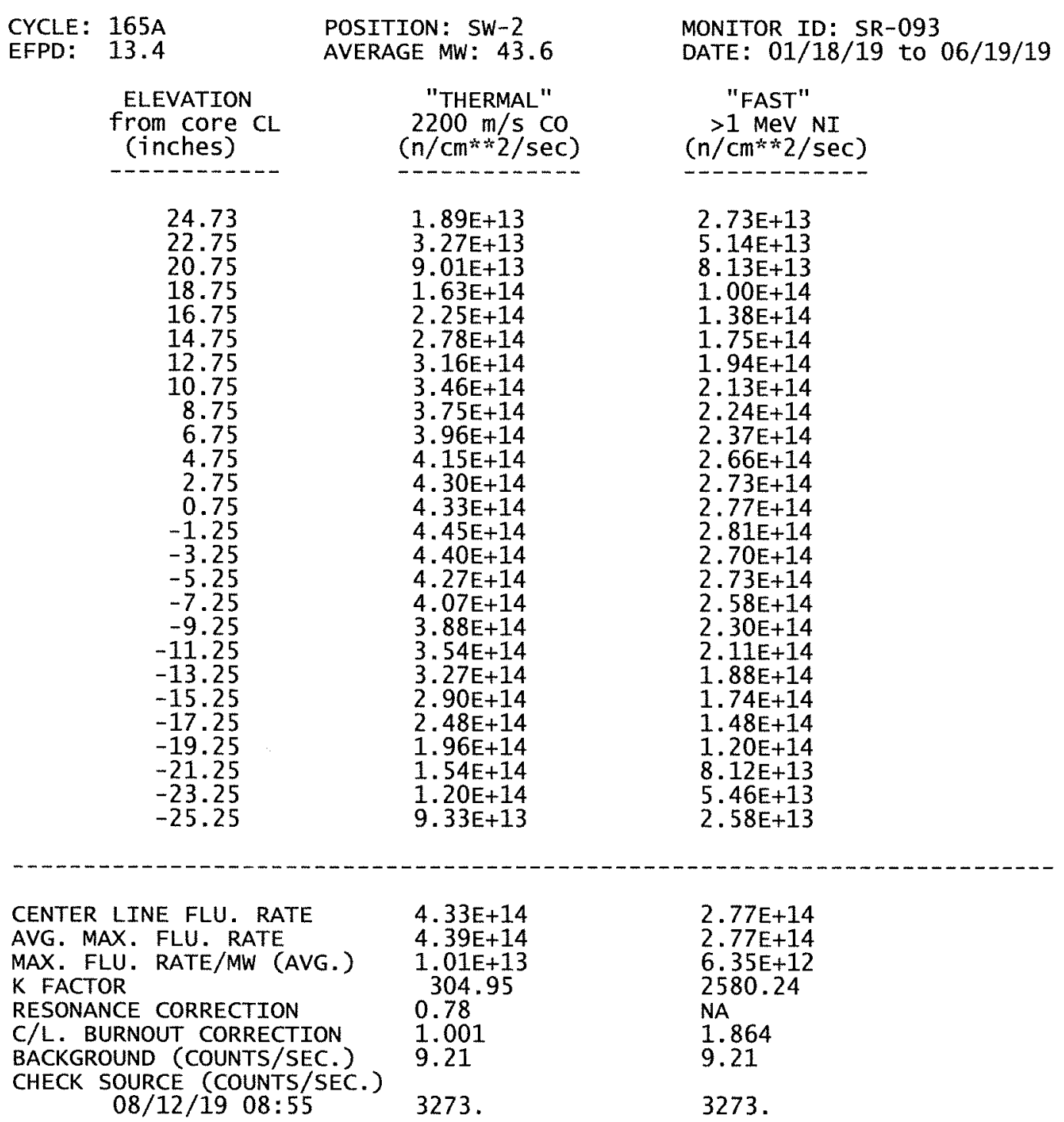


ATR NEUTRON MONITOR RESULTS

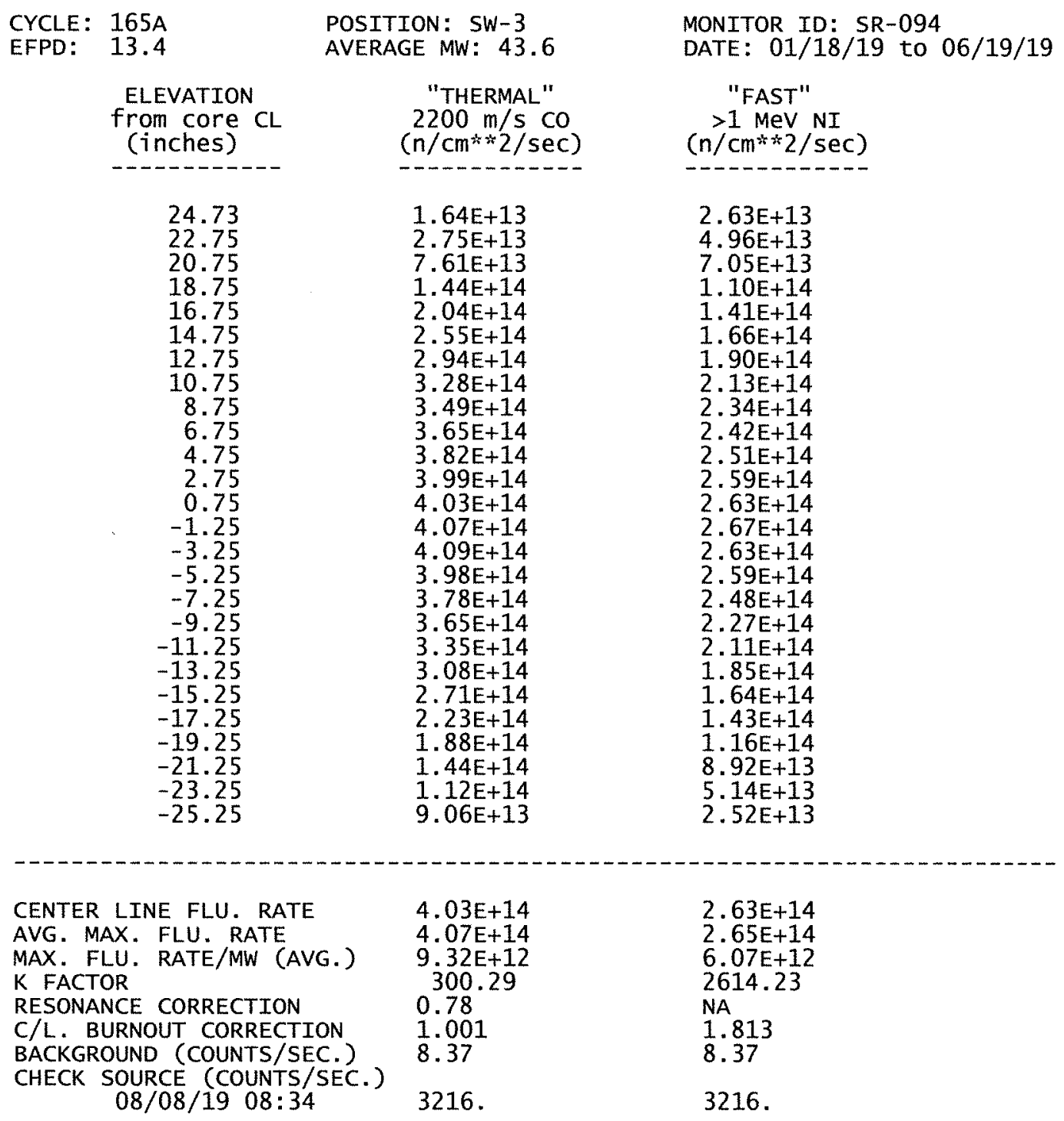


ATR NEUTRON MONITOR RESULTS

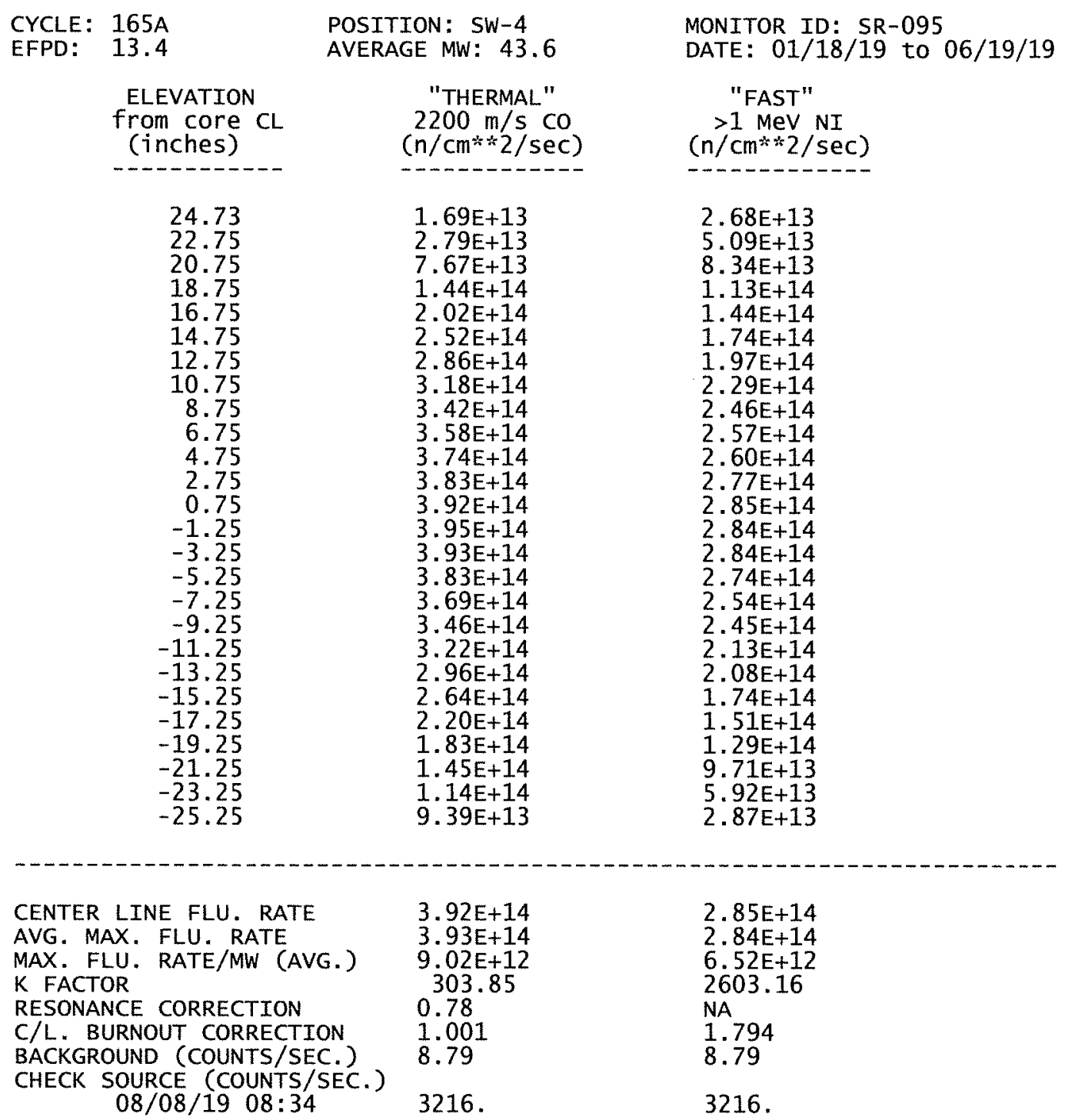


ATR NEUTRON MONITOR RESULTS

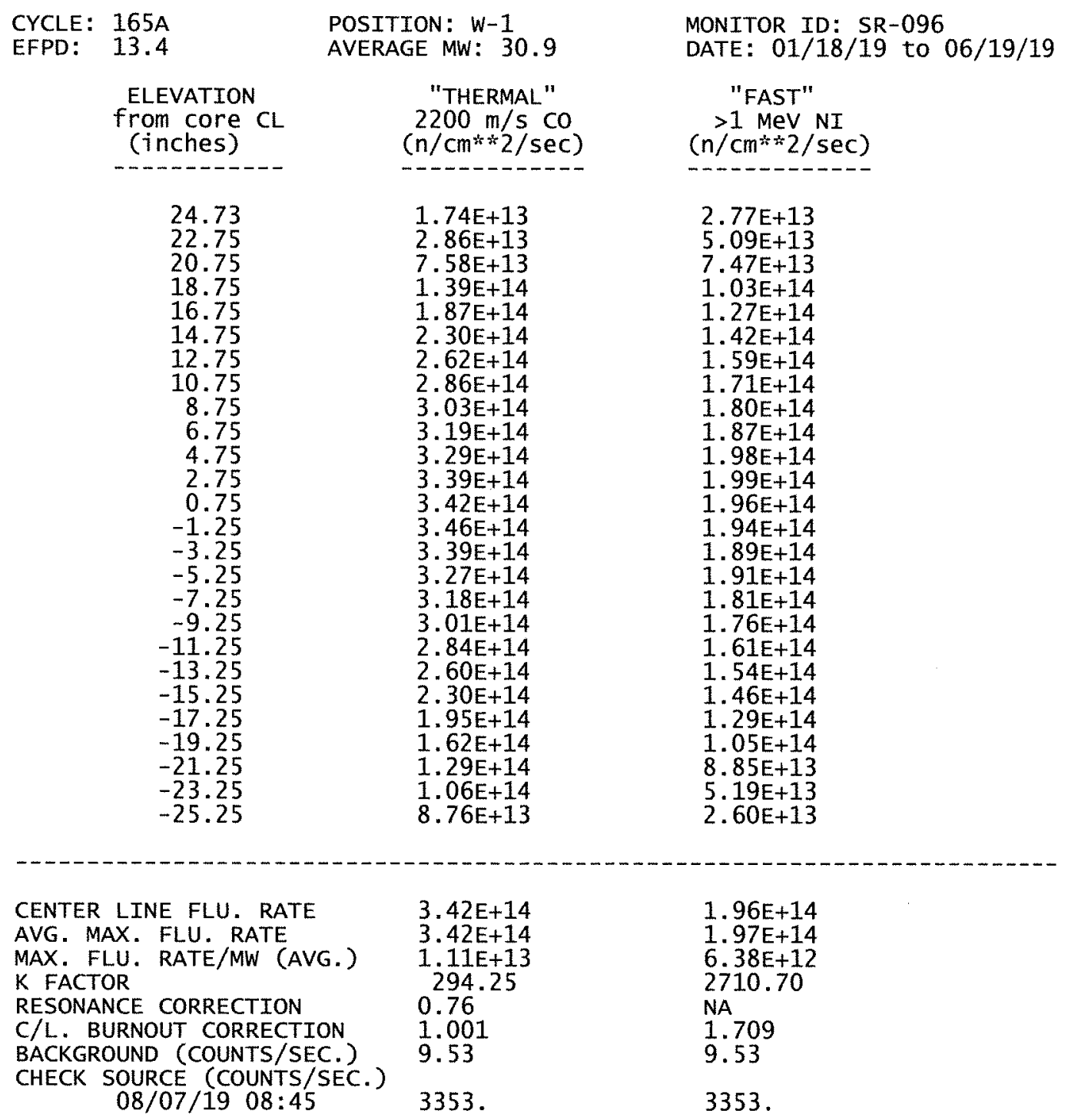


ATR NEUTRON MONITOR RESULTS

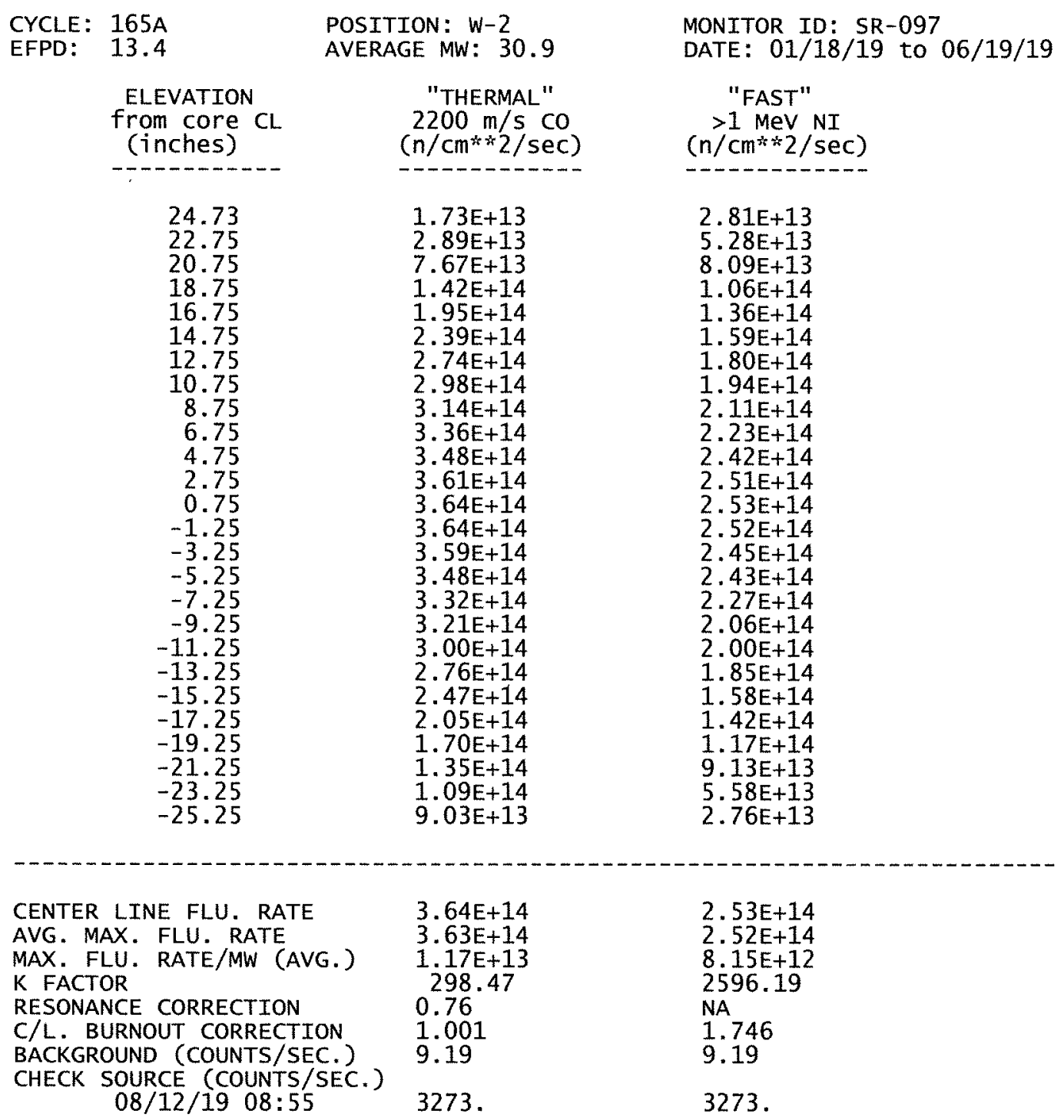


ATR NEUTRON MONITOR RESULTS

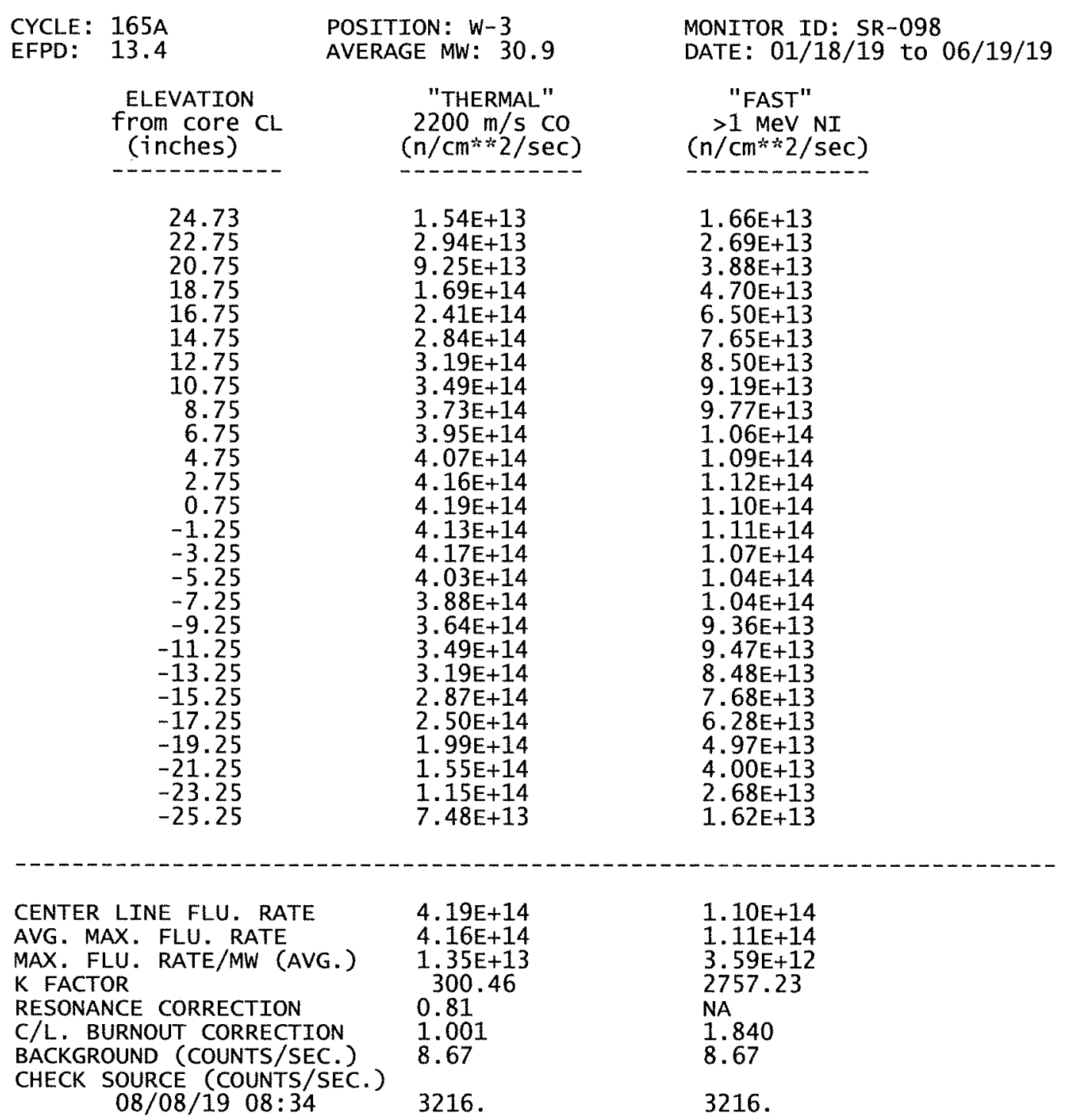


ATR NEUTRON MONTTOR RESULTS

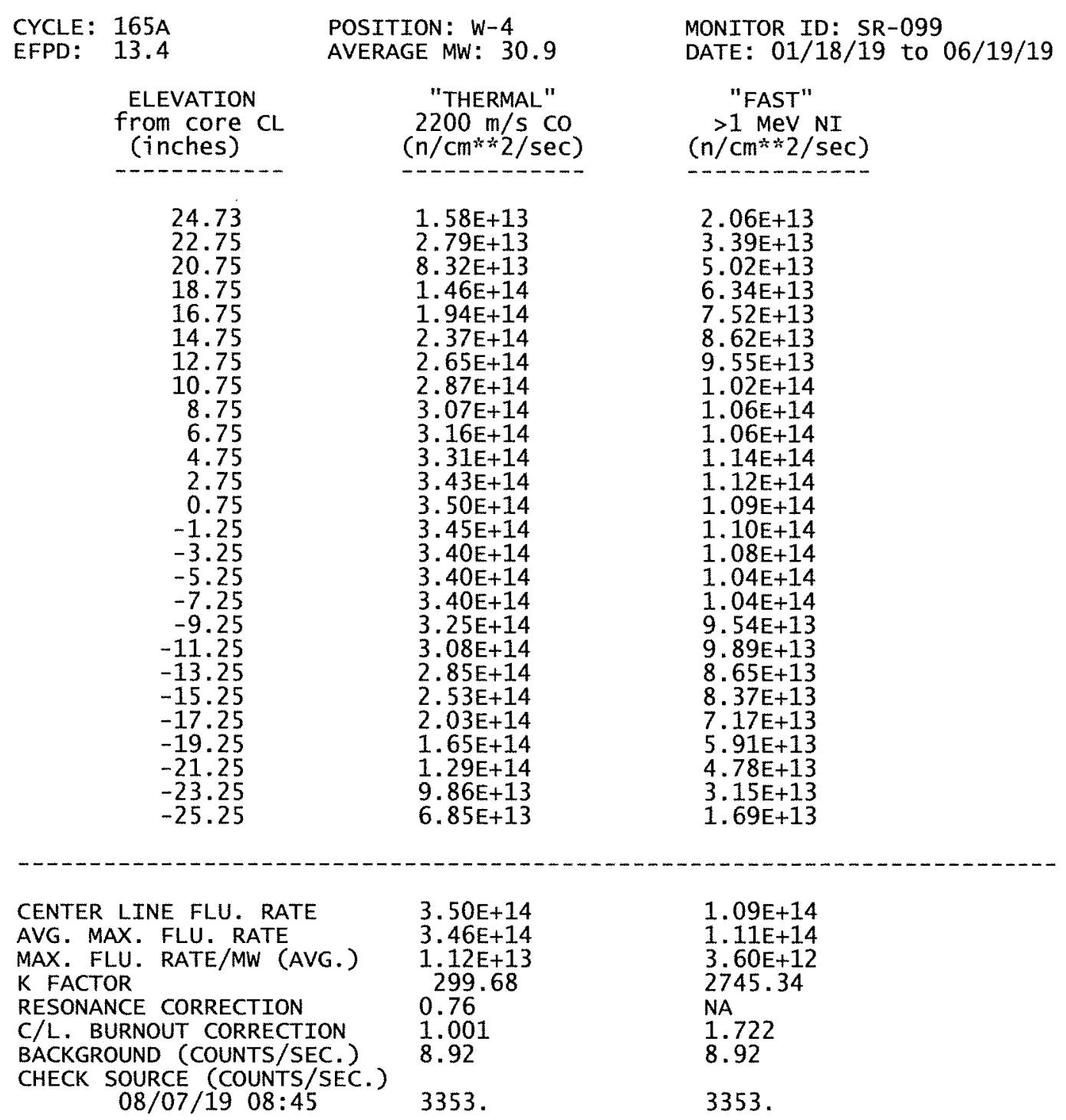




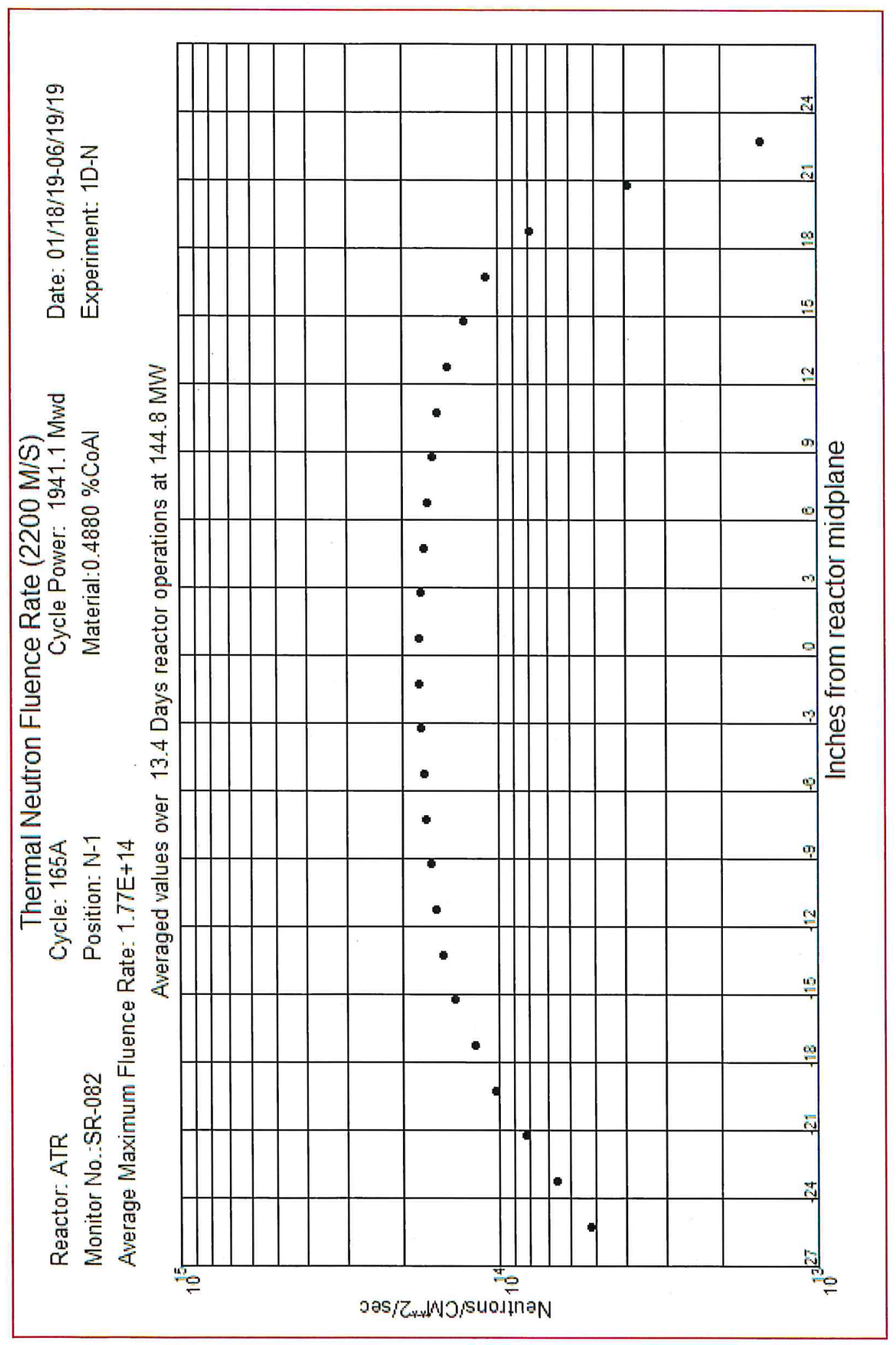




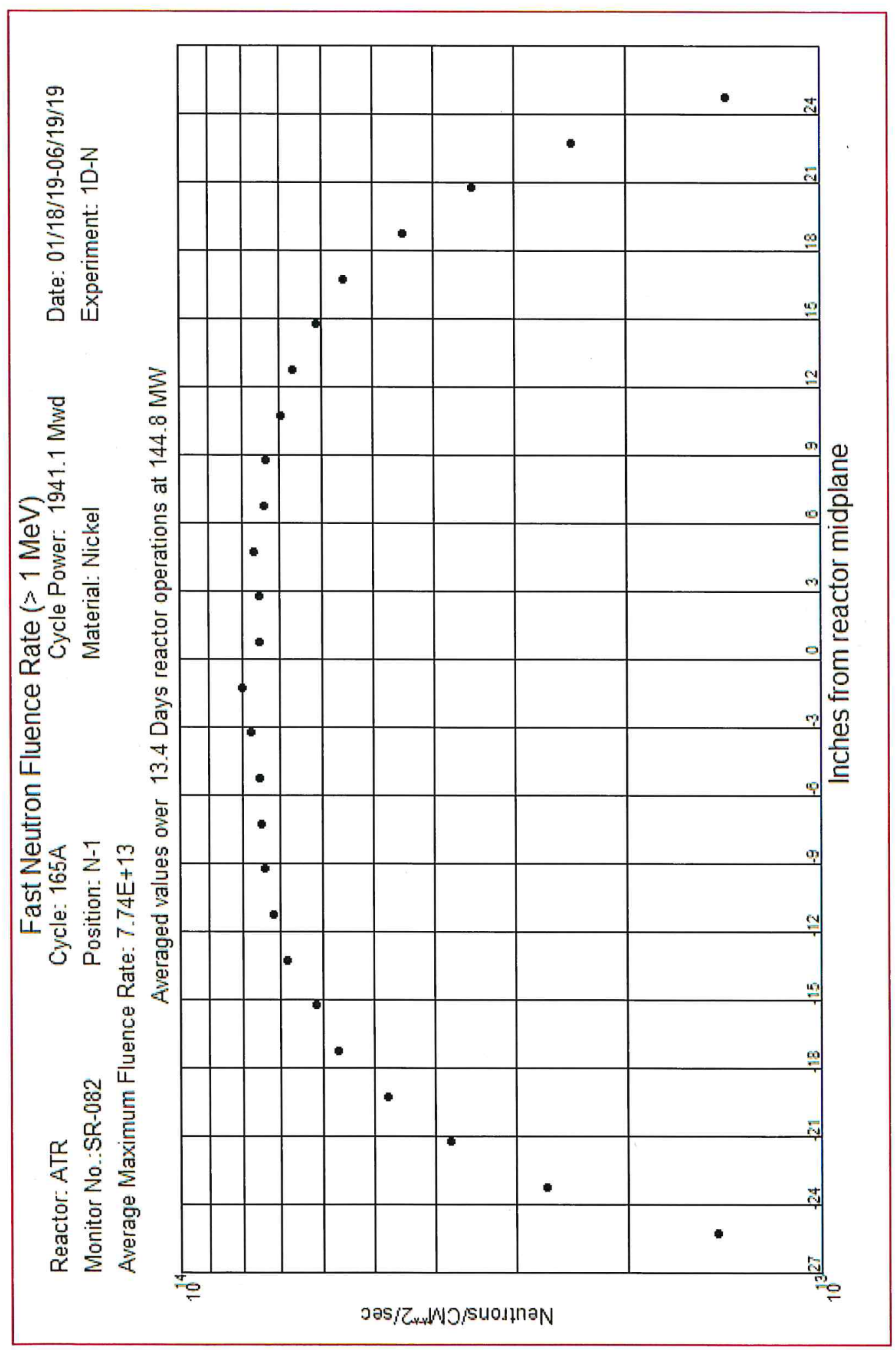




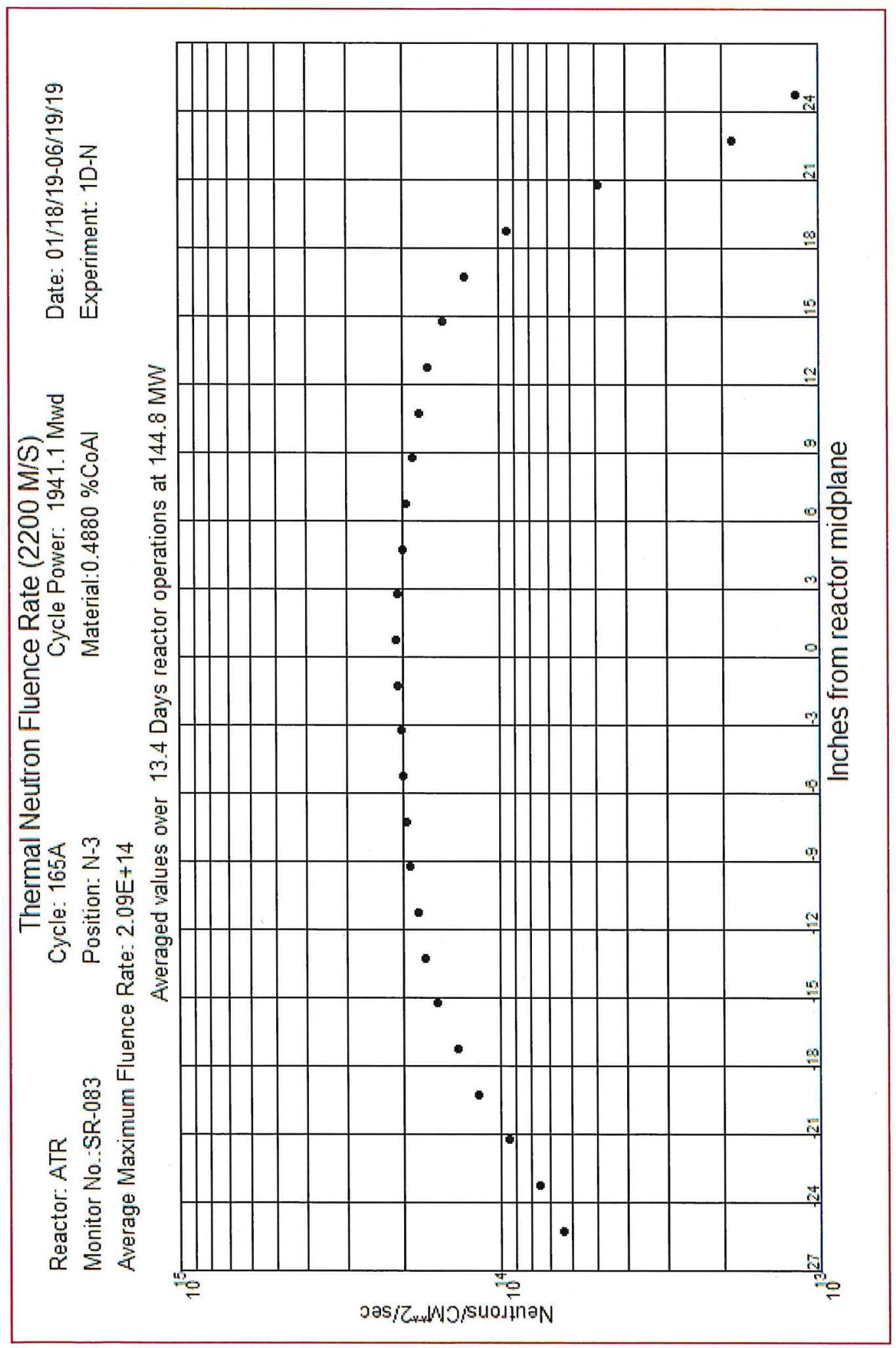




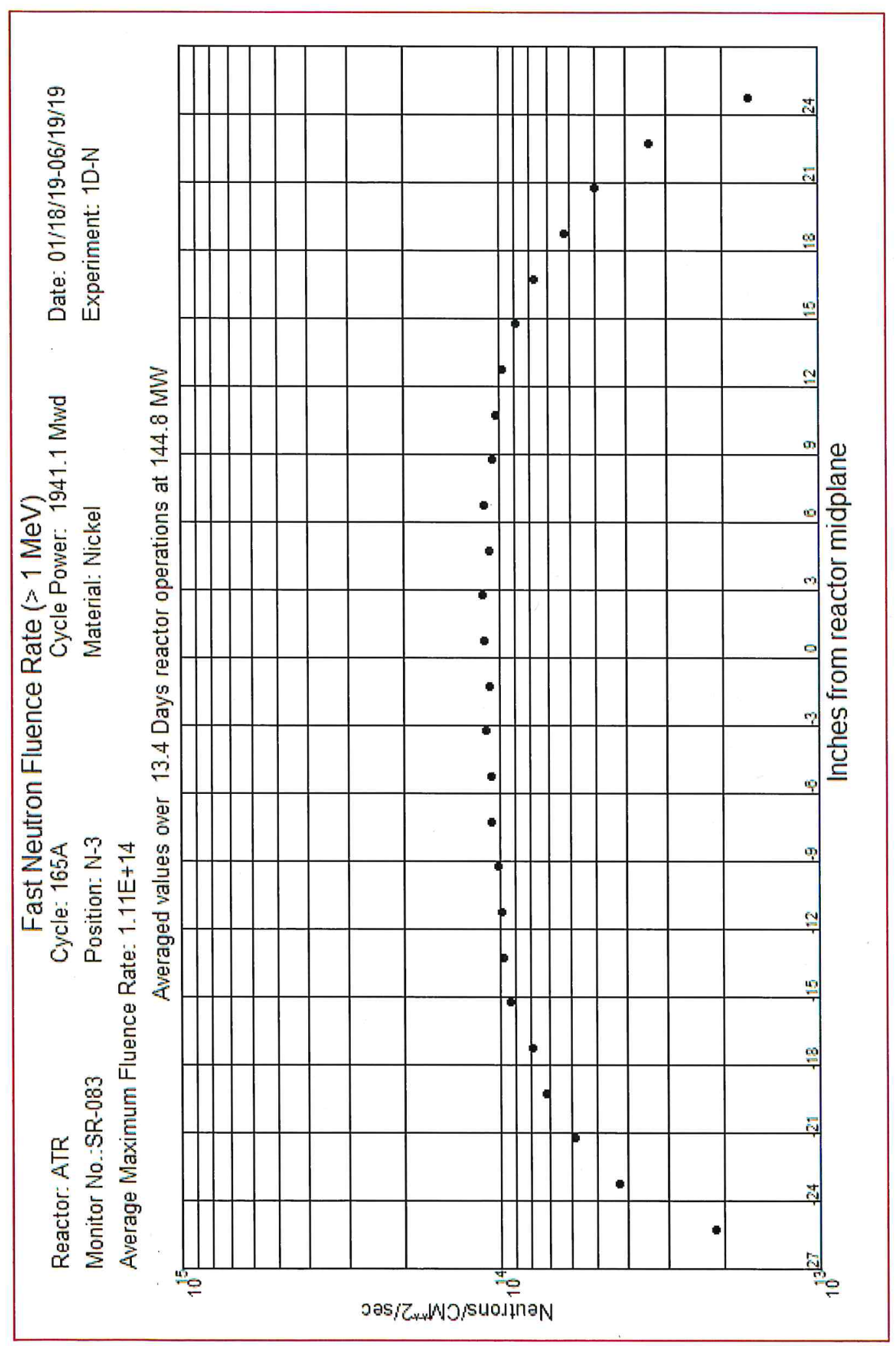




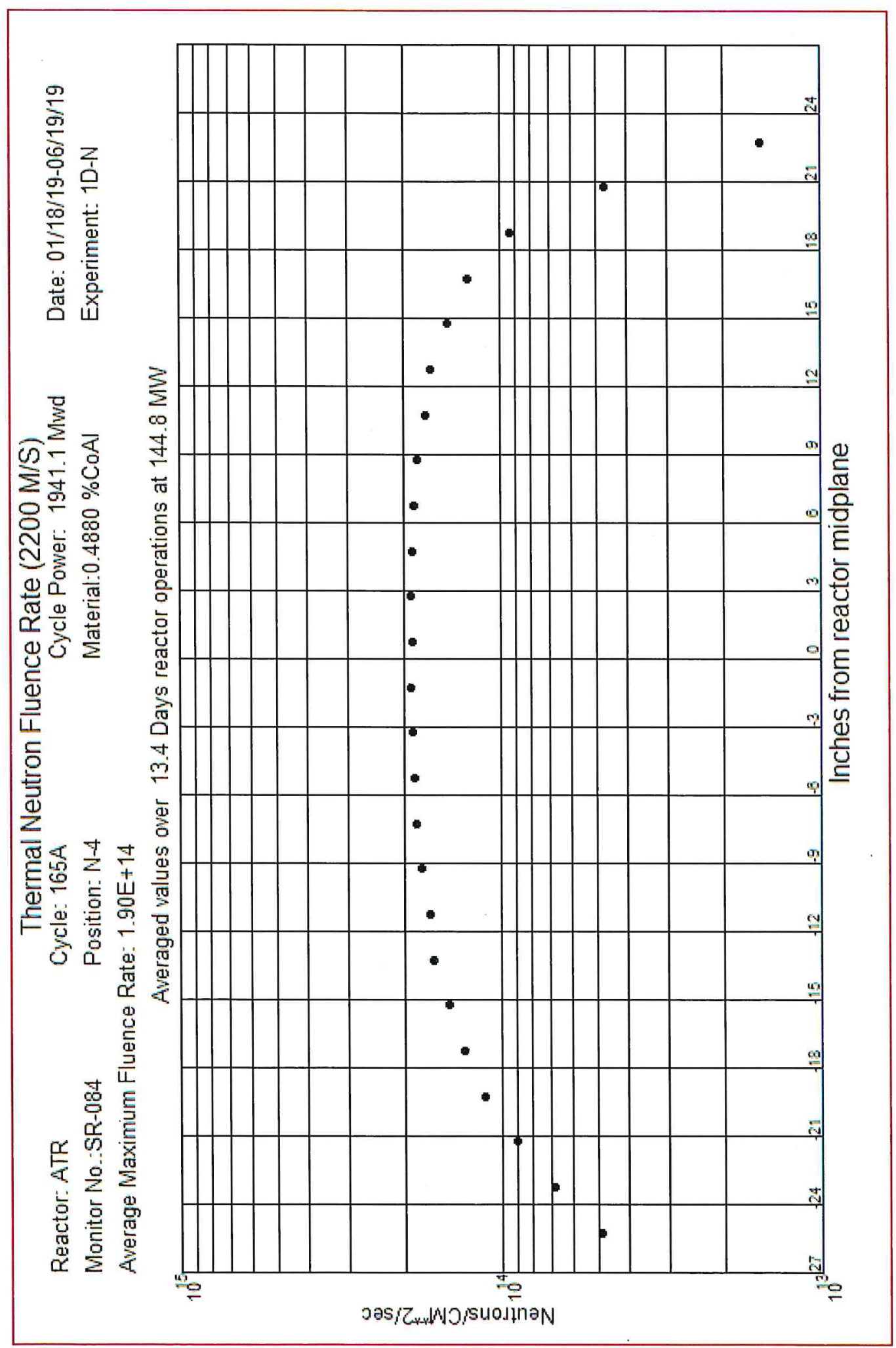




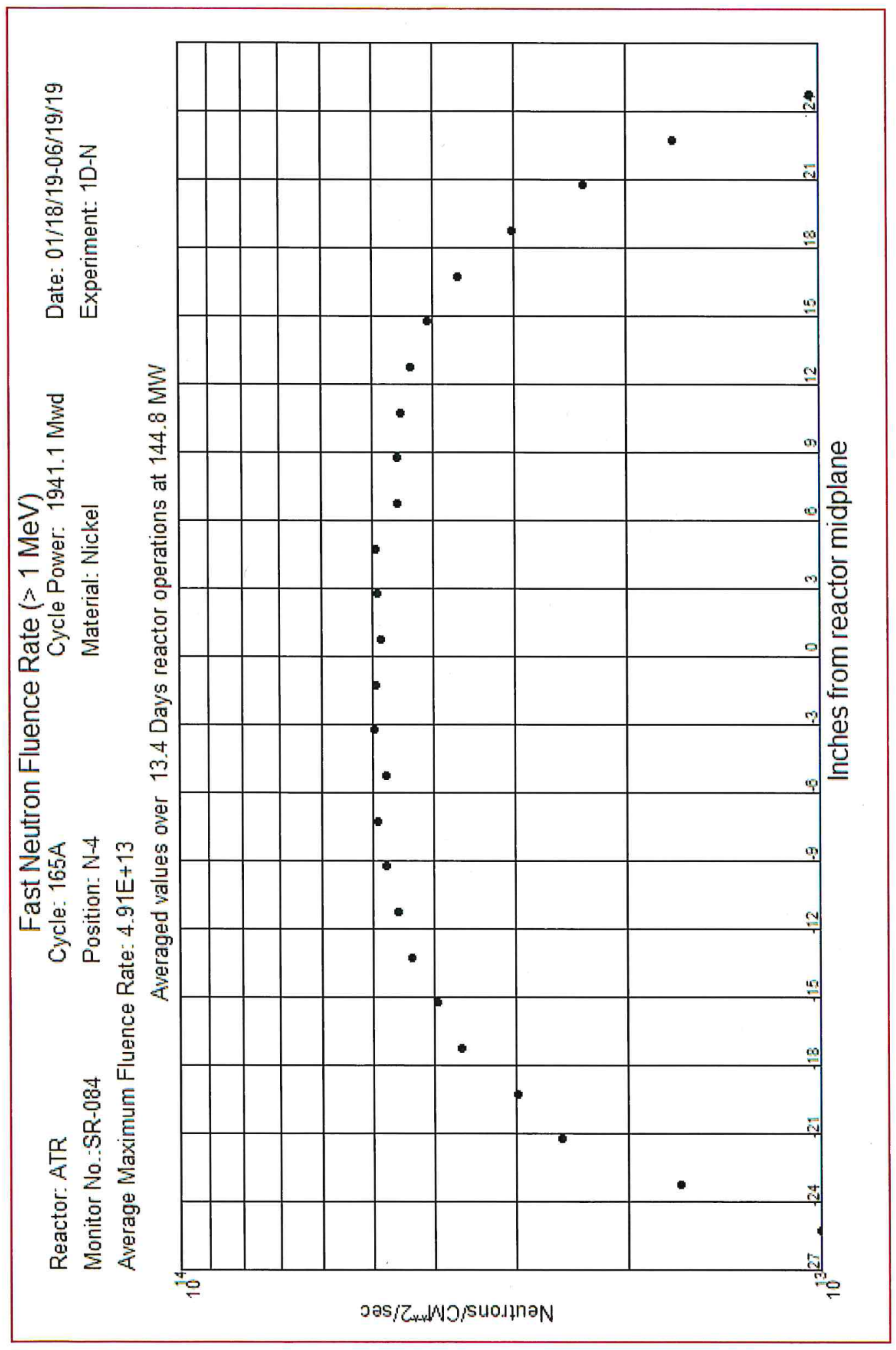




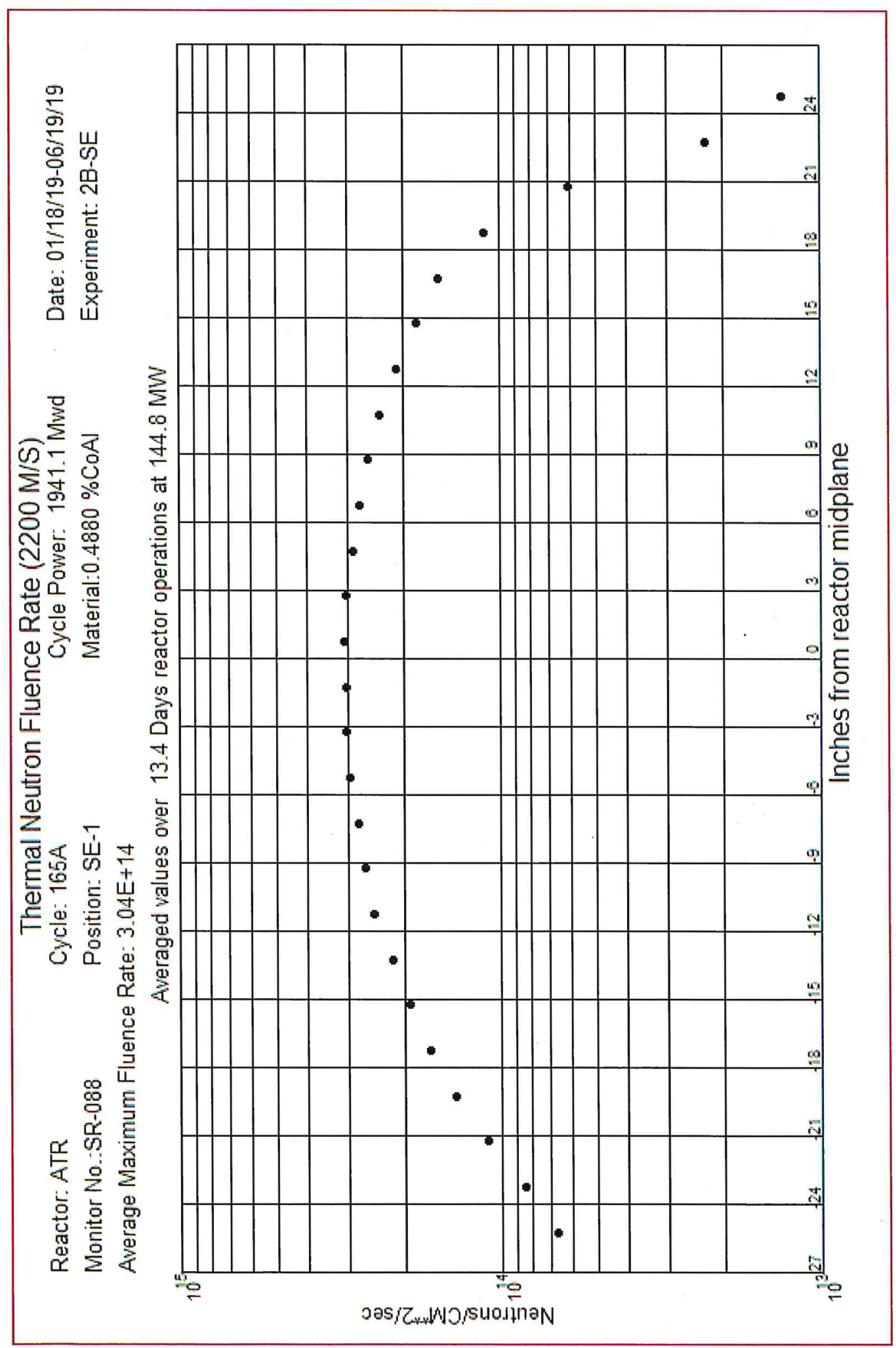




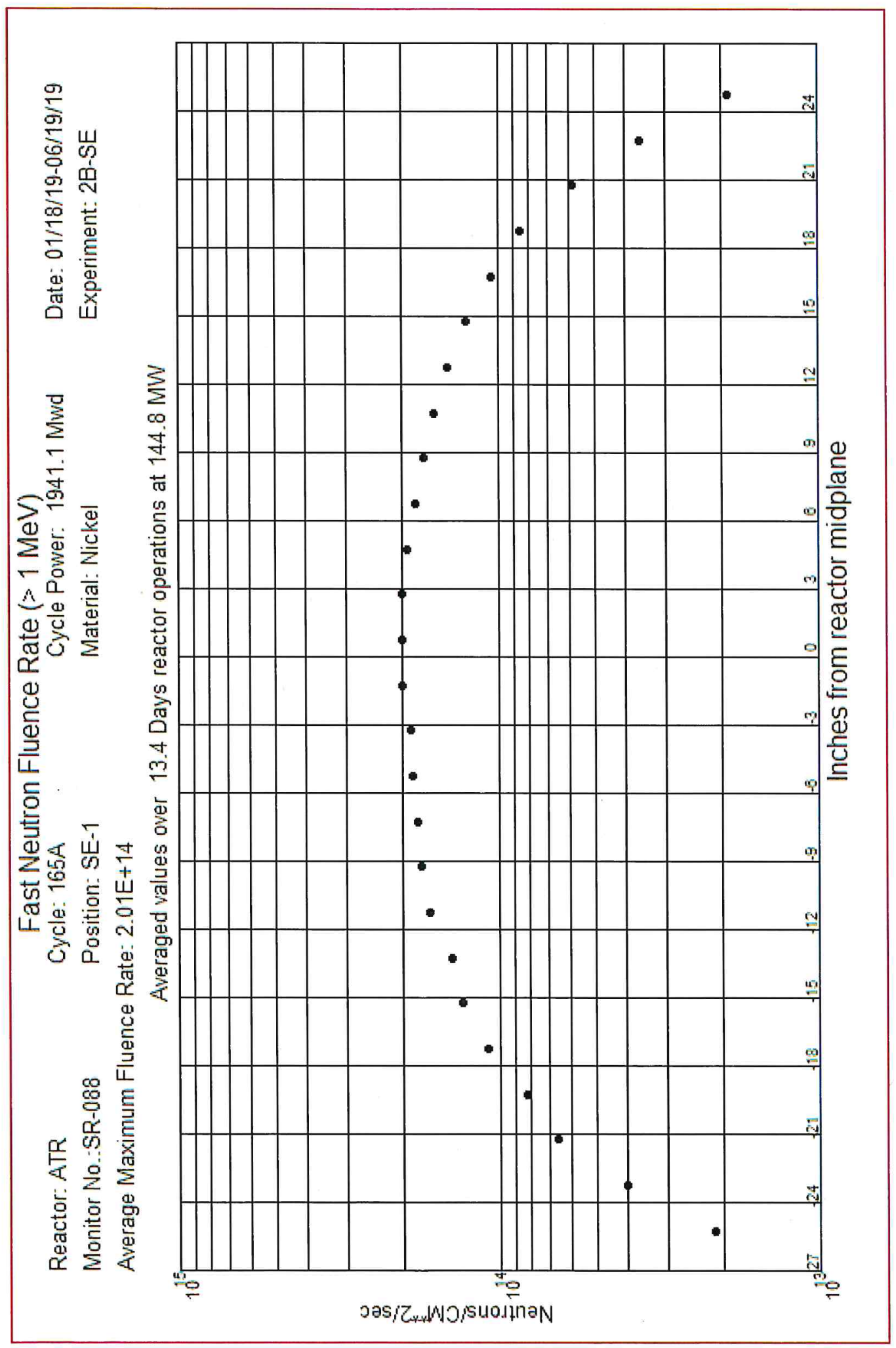




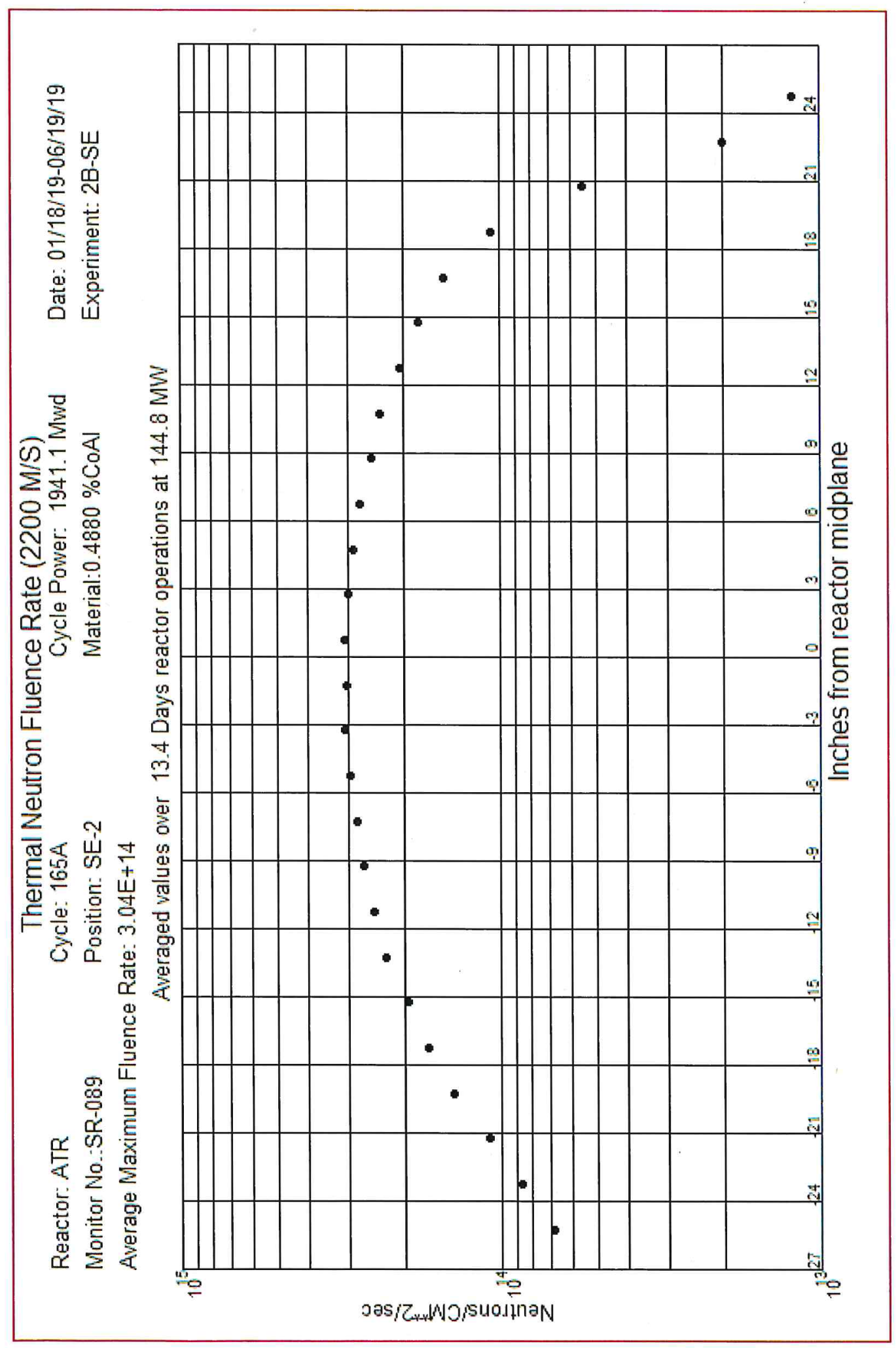




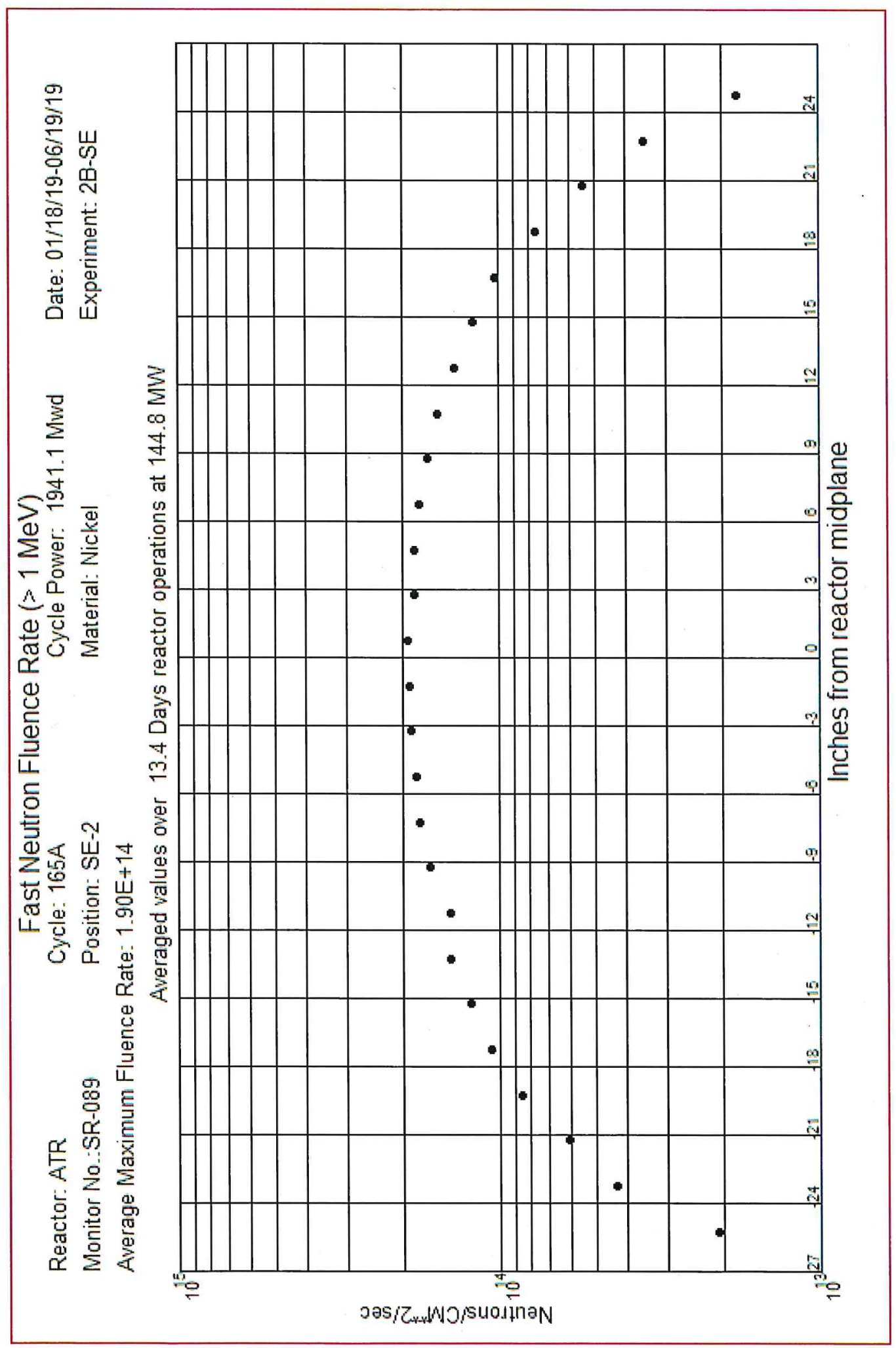




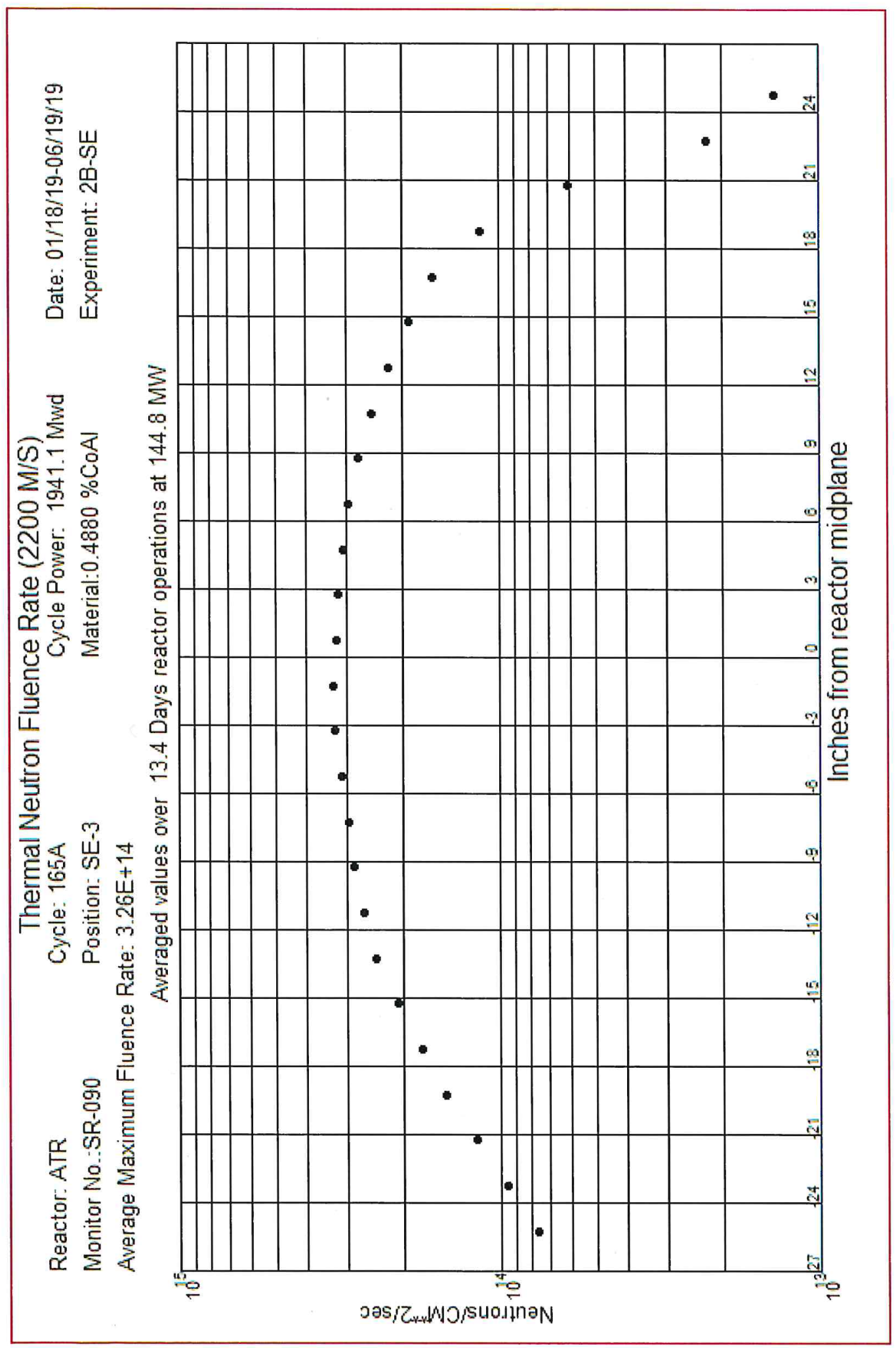




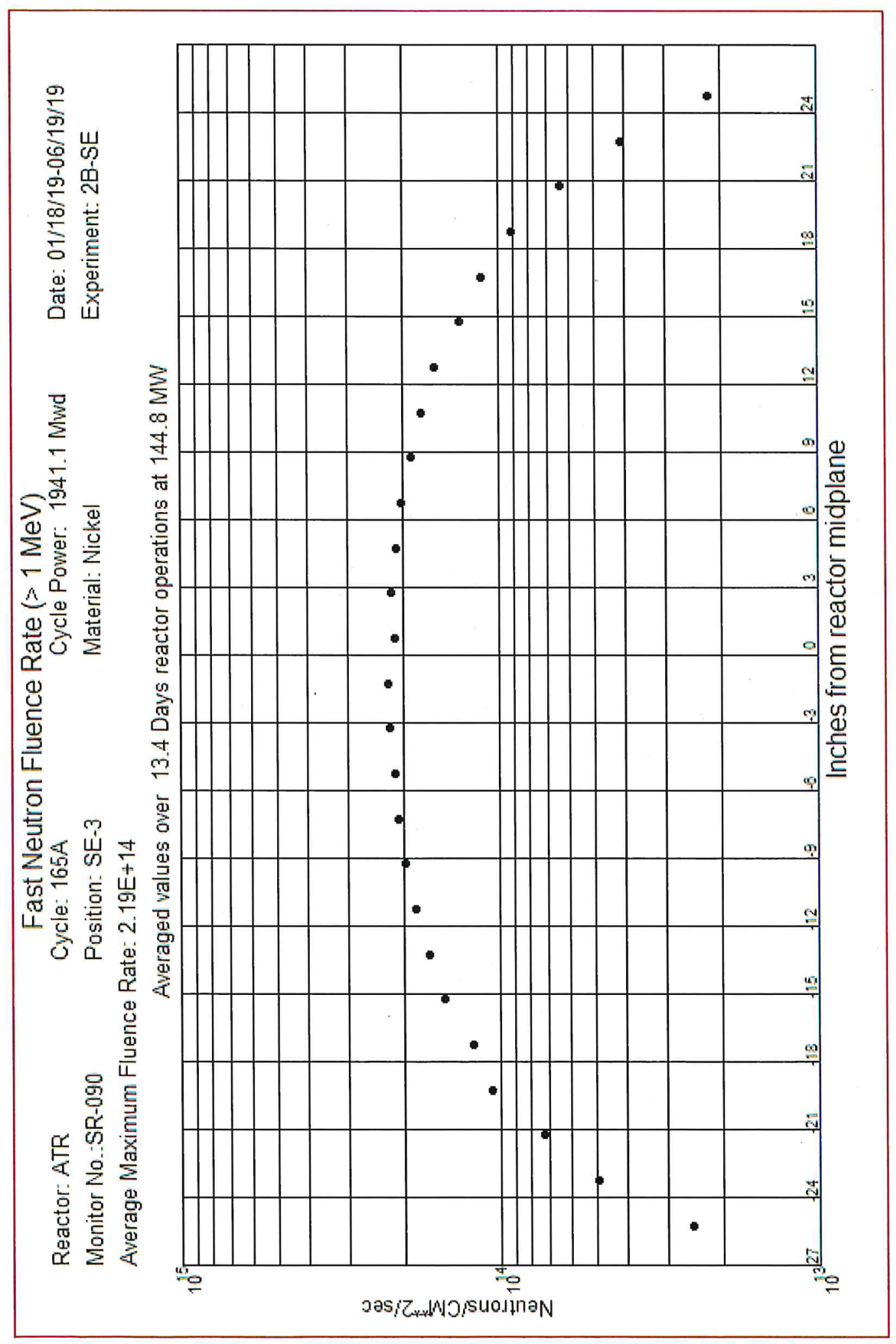




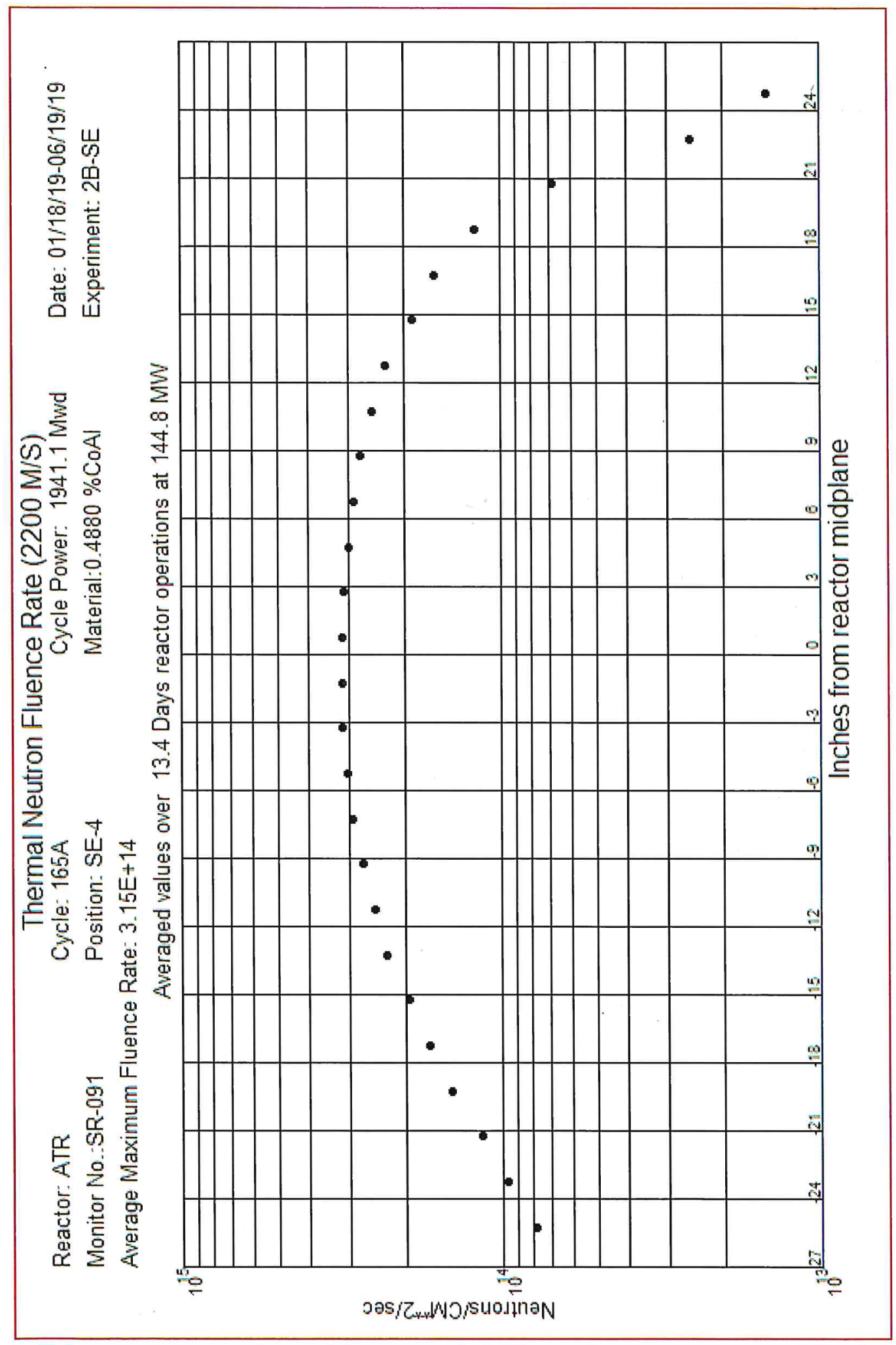




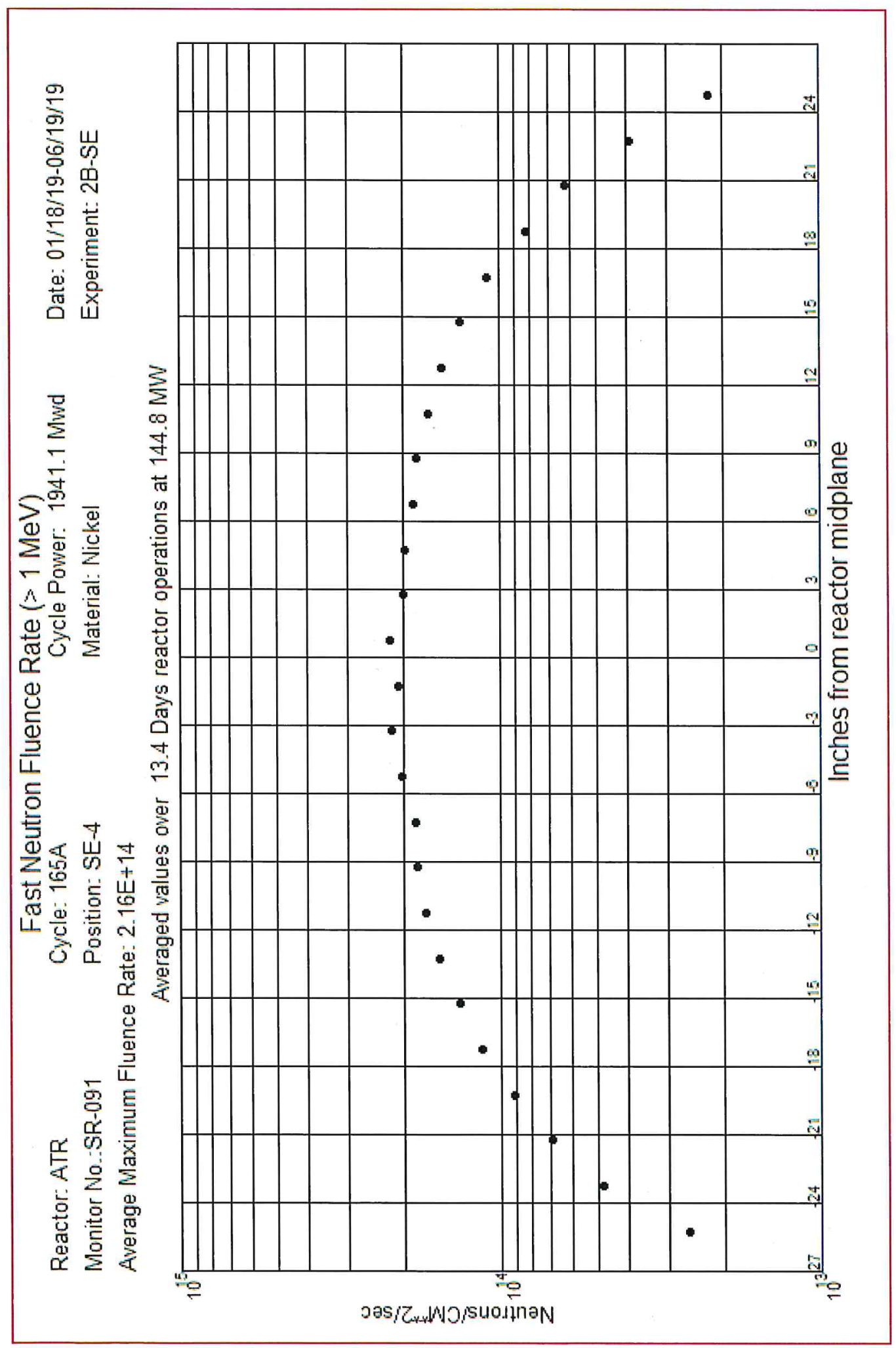




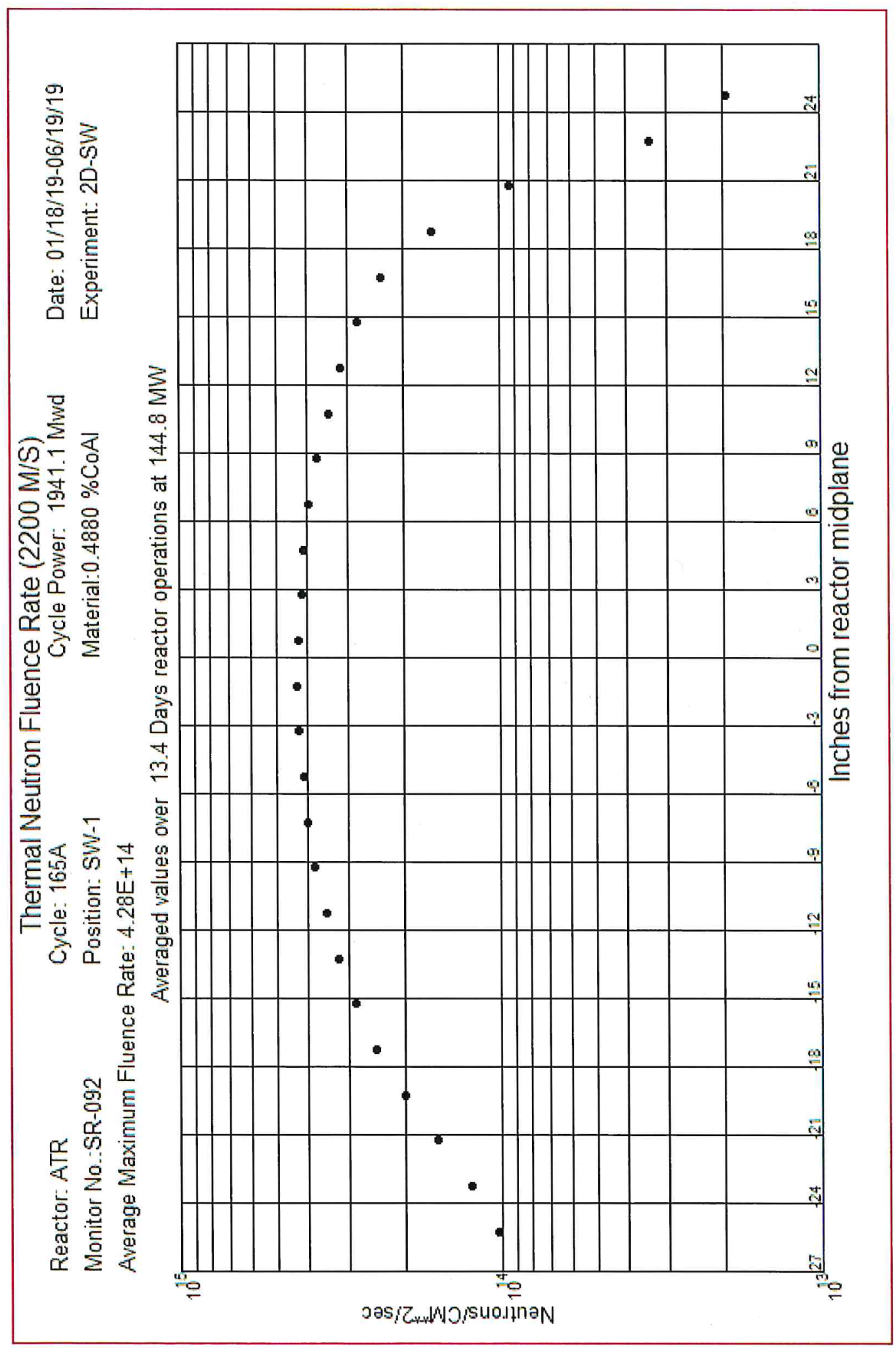




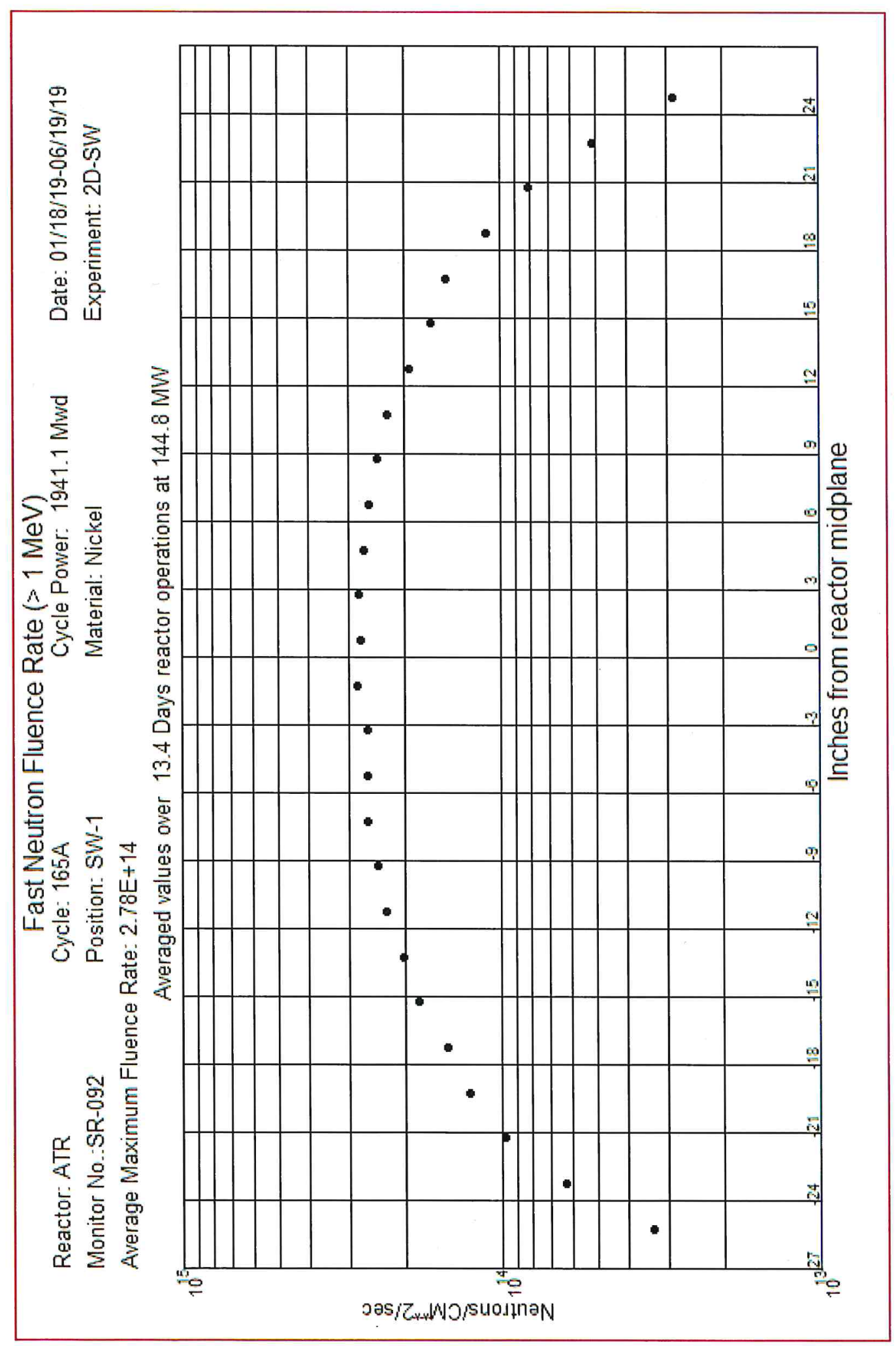




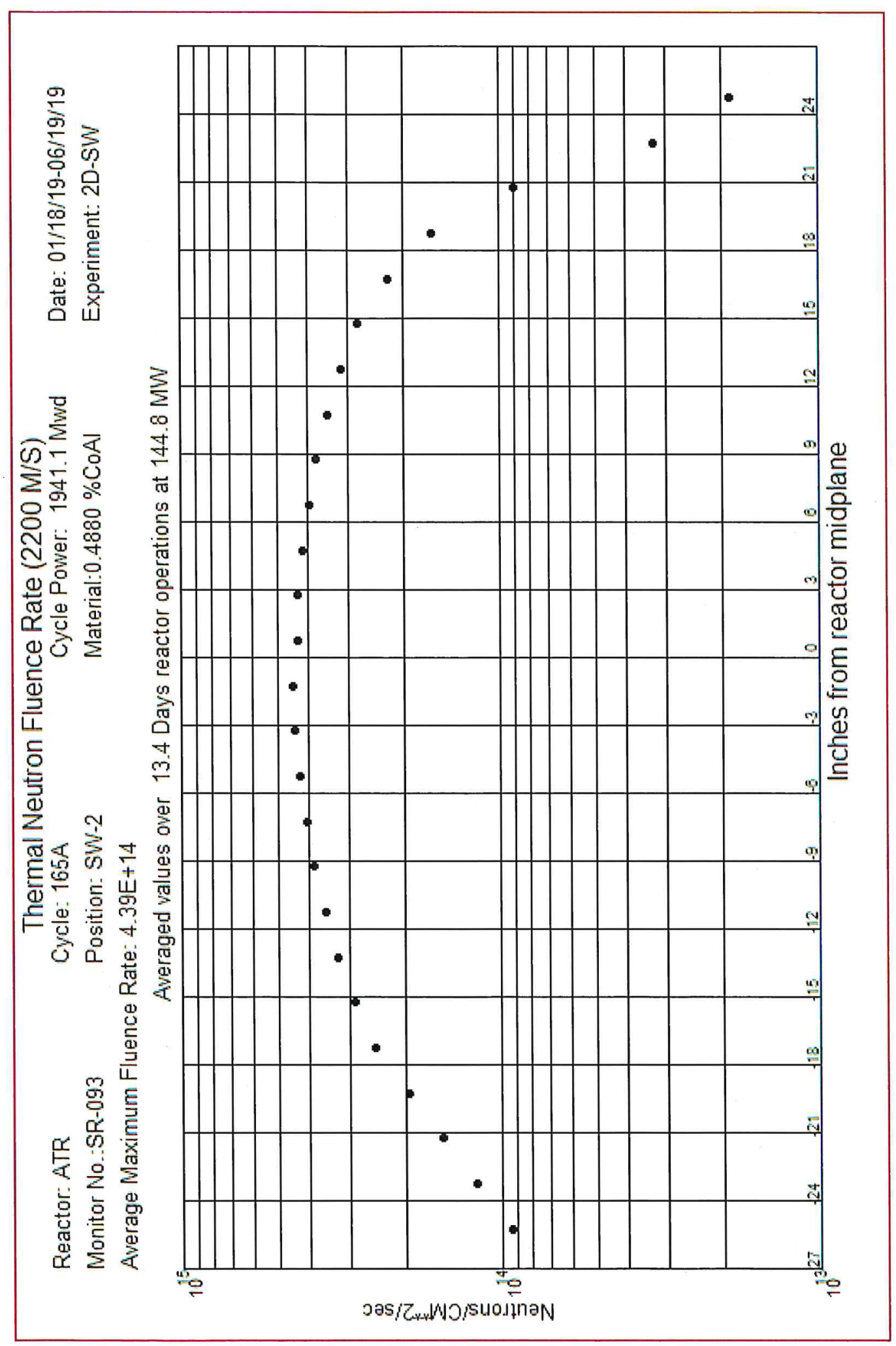




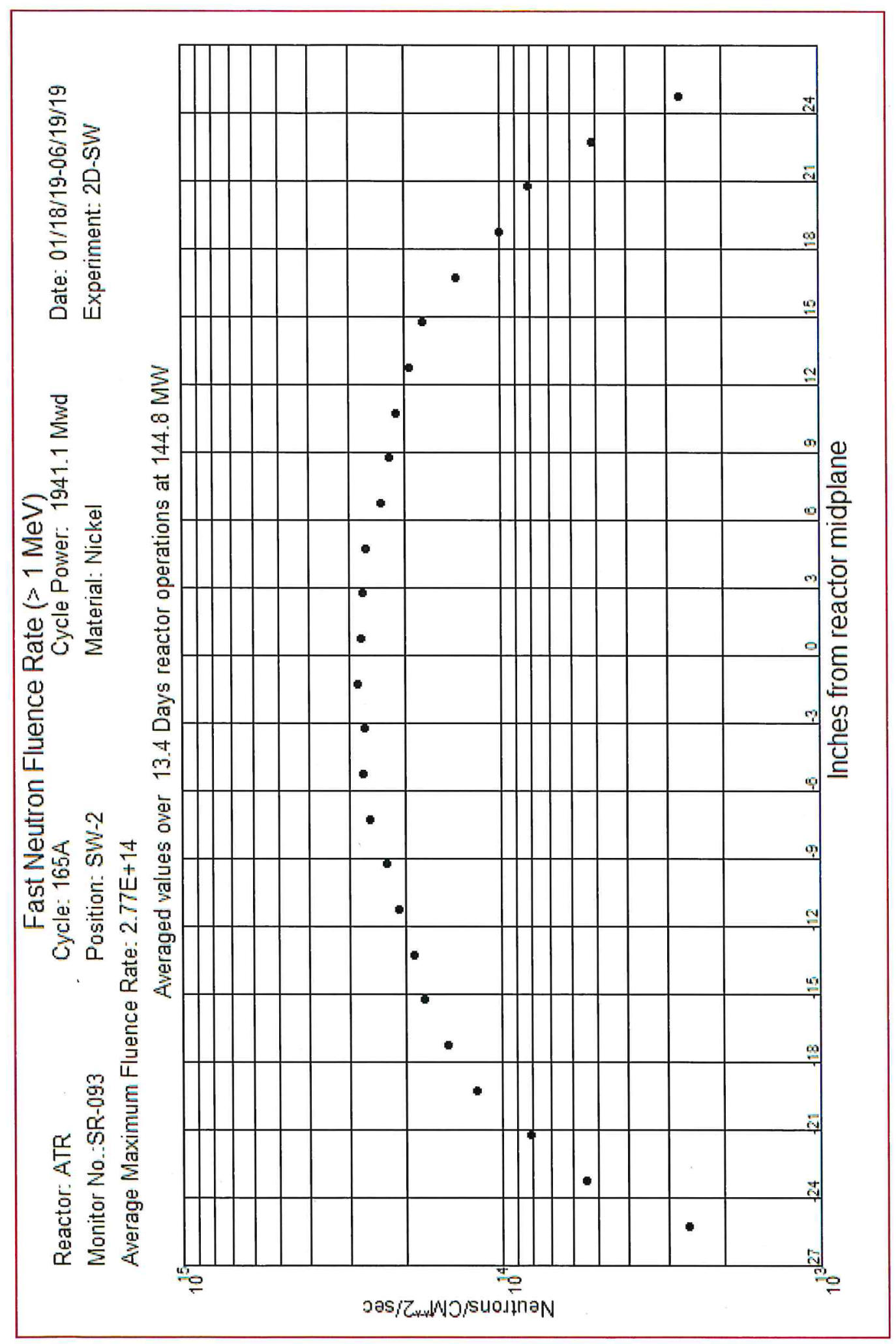




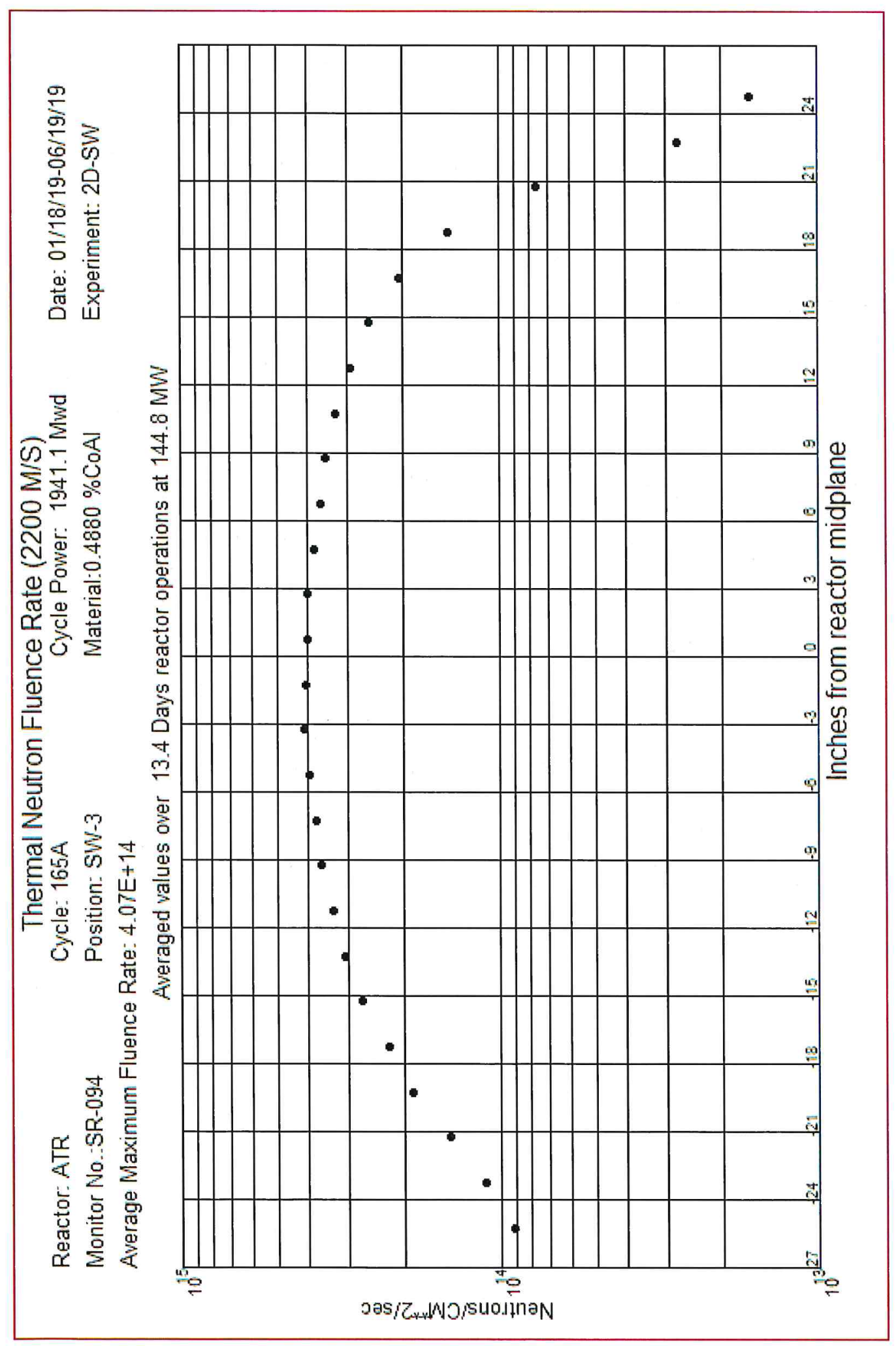




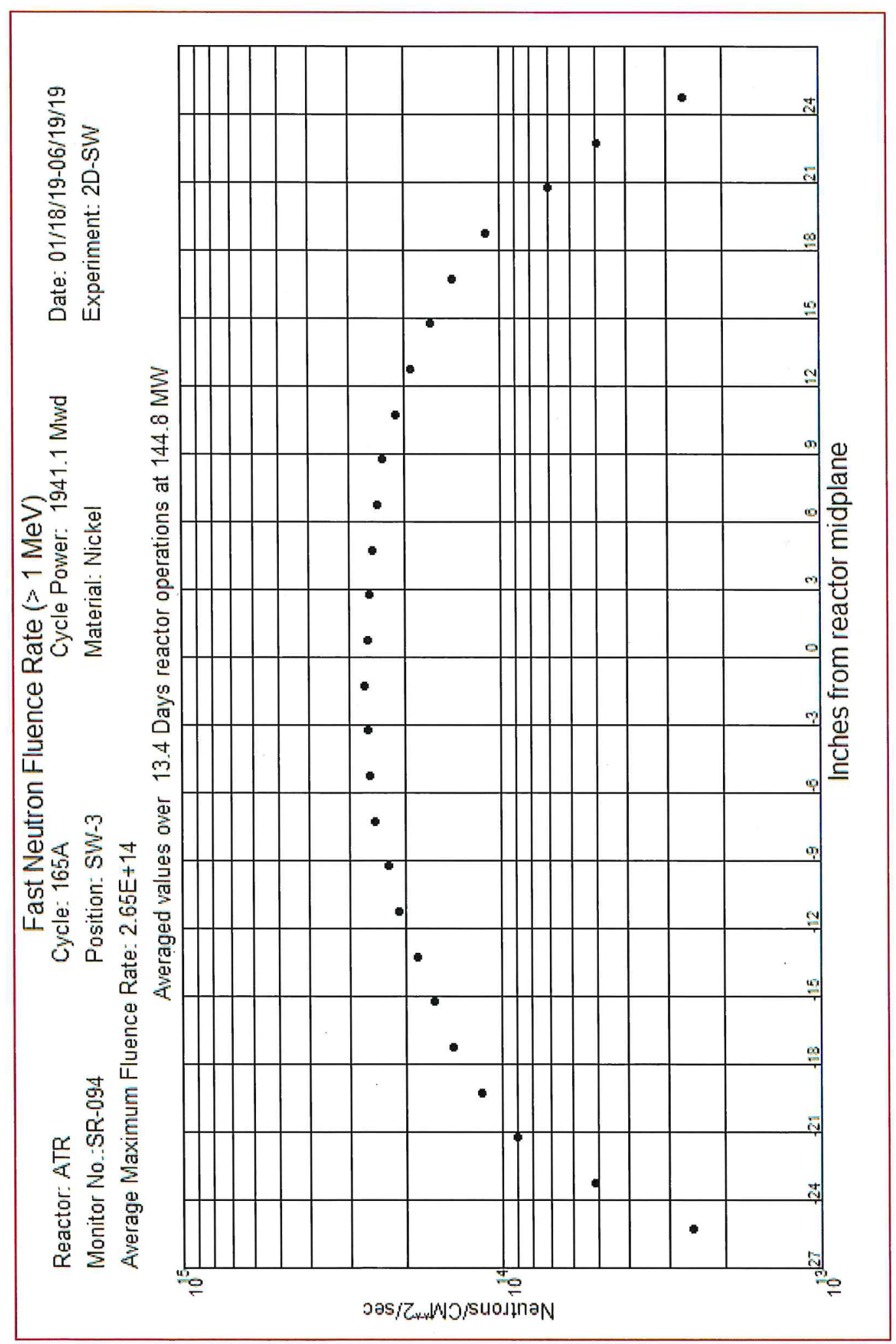




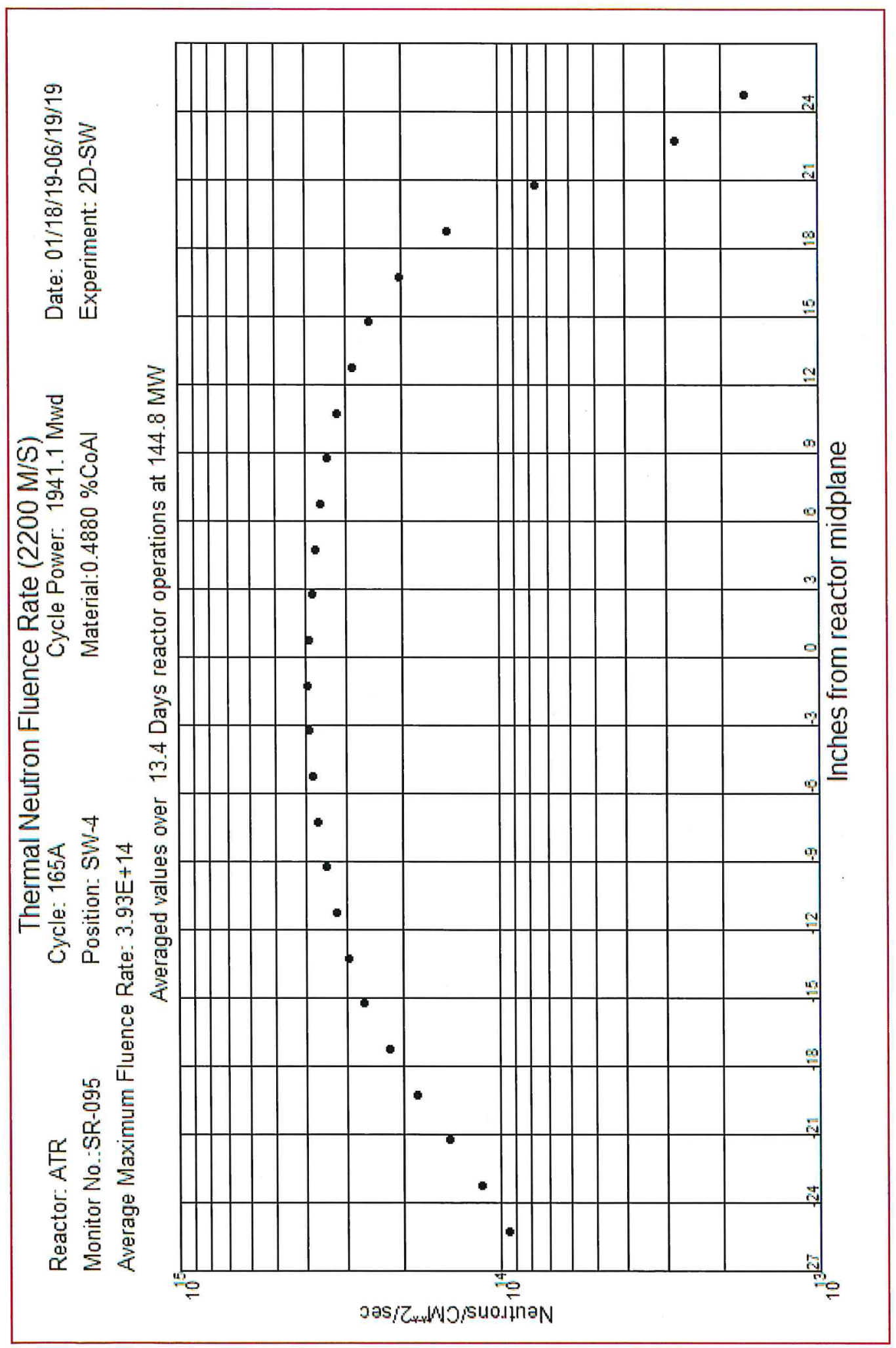




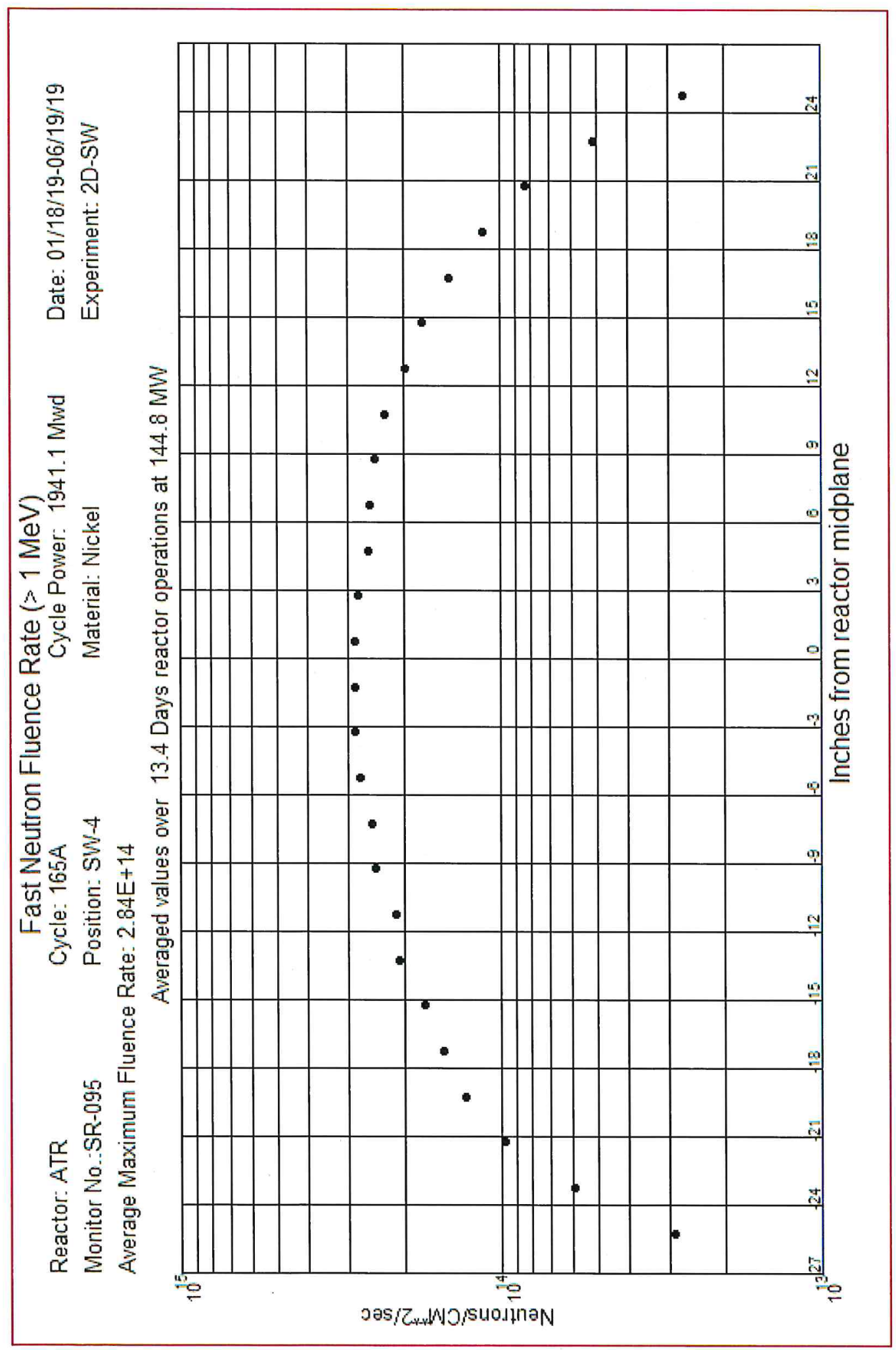




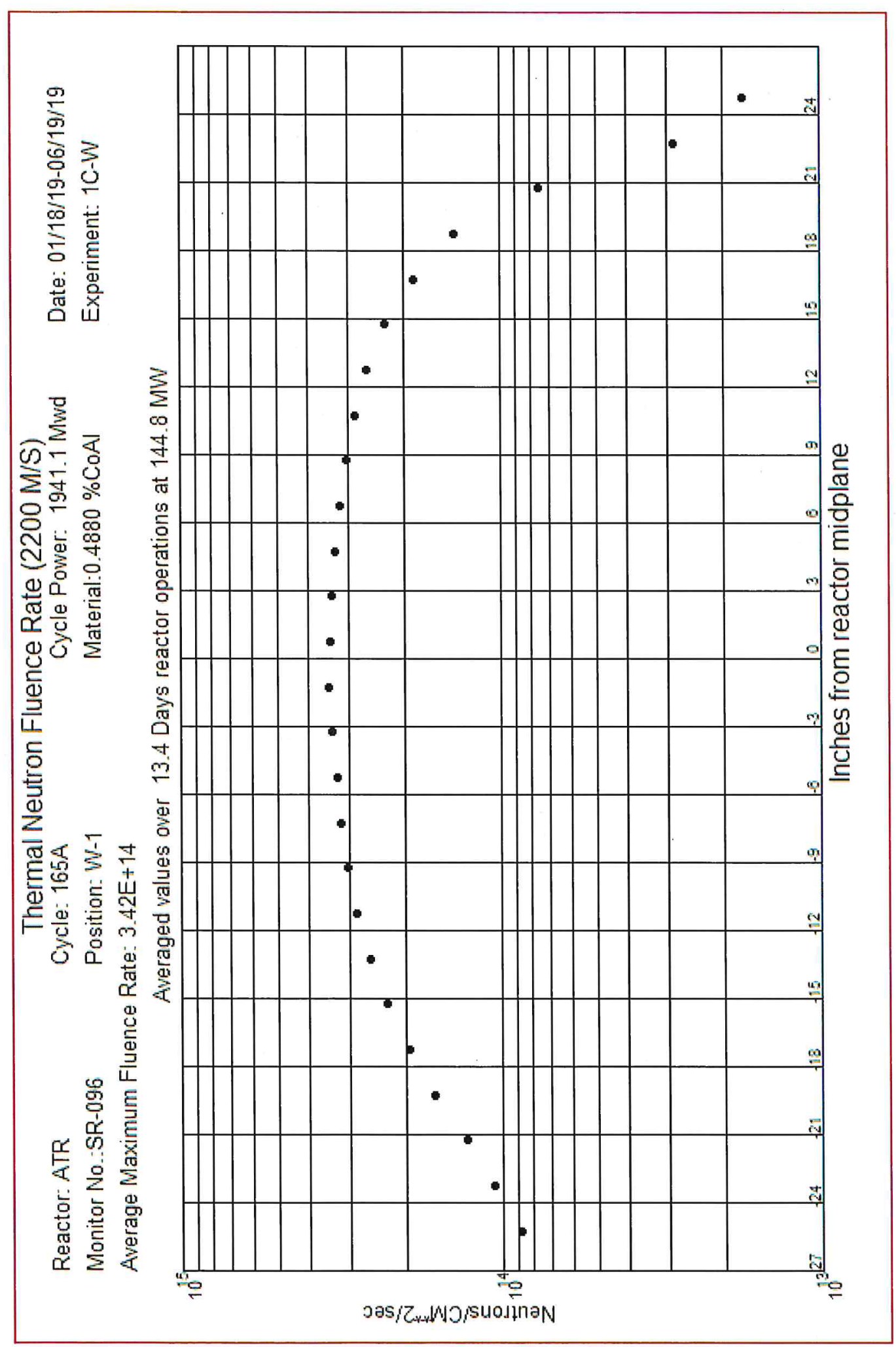




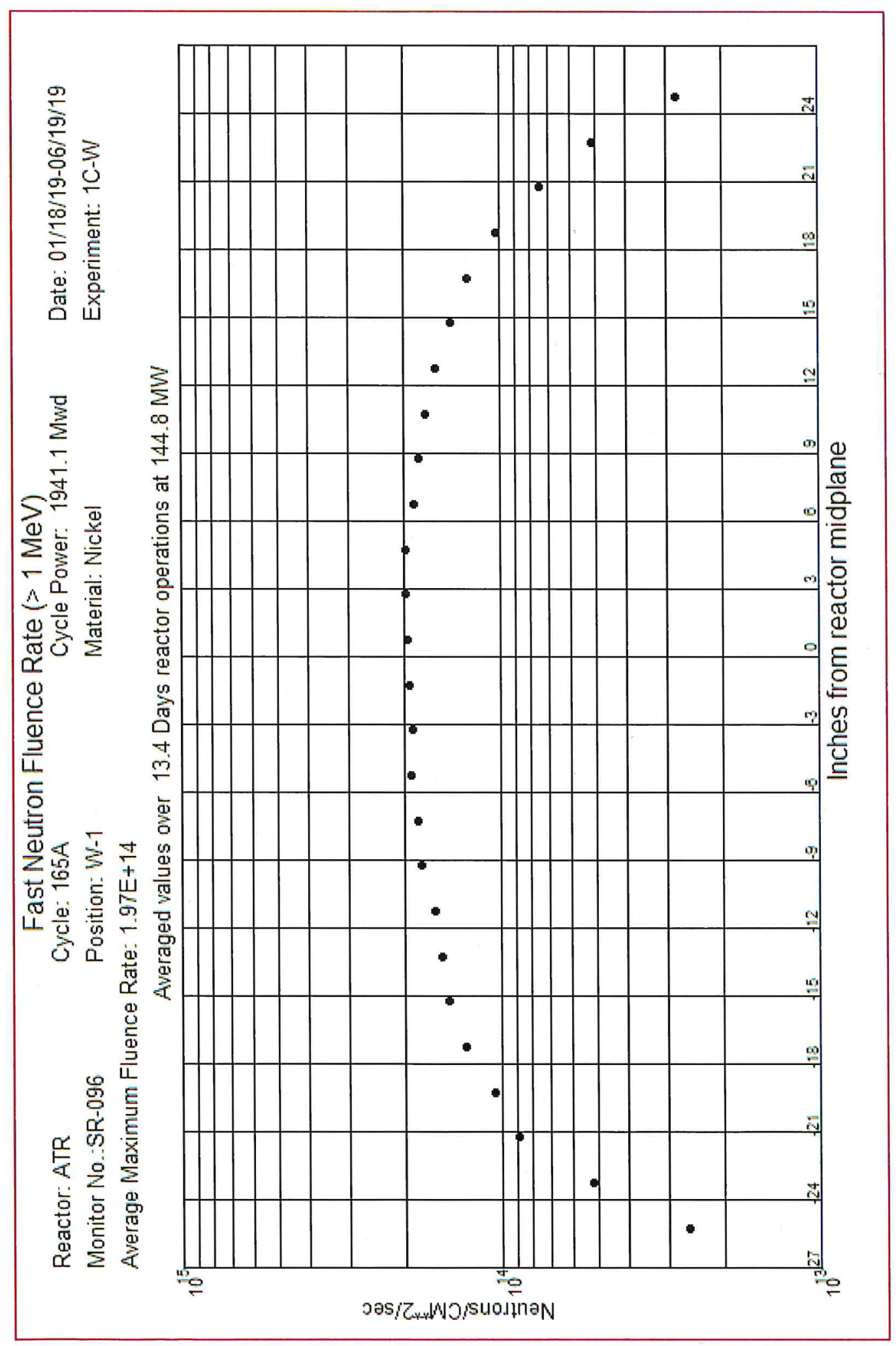




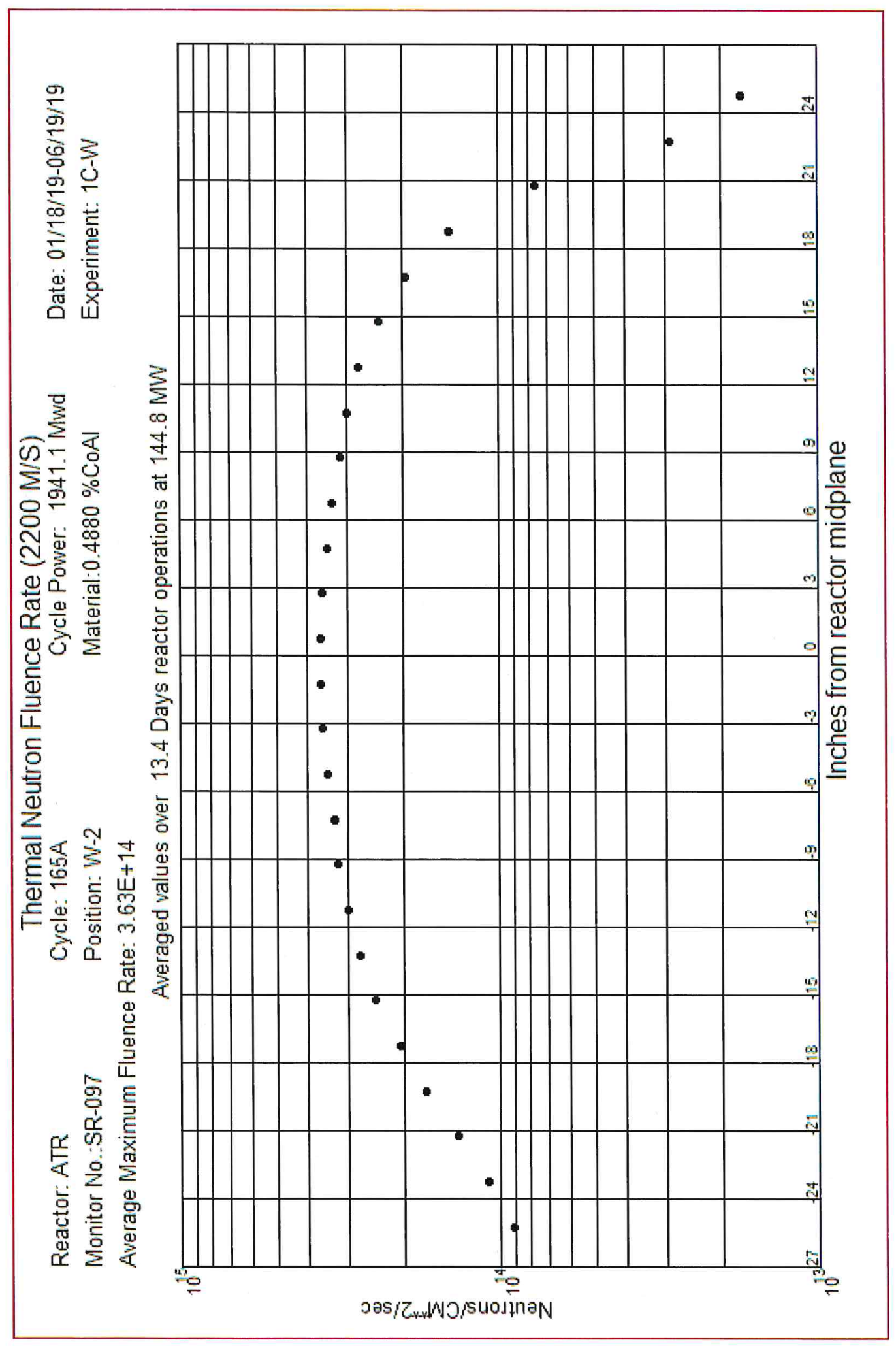




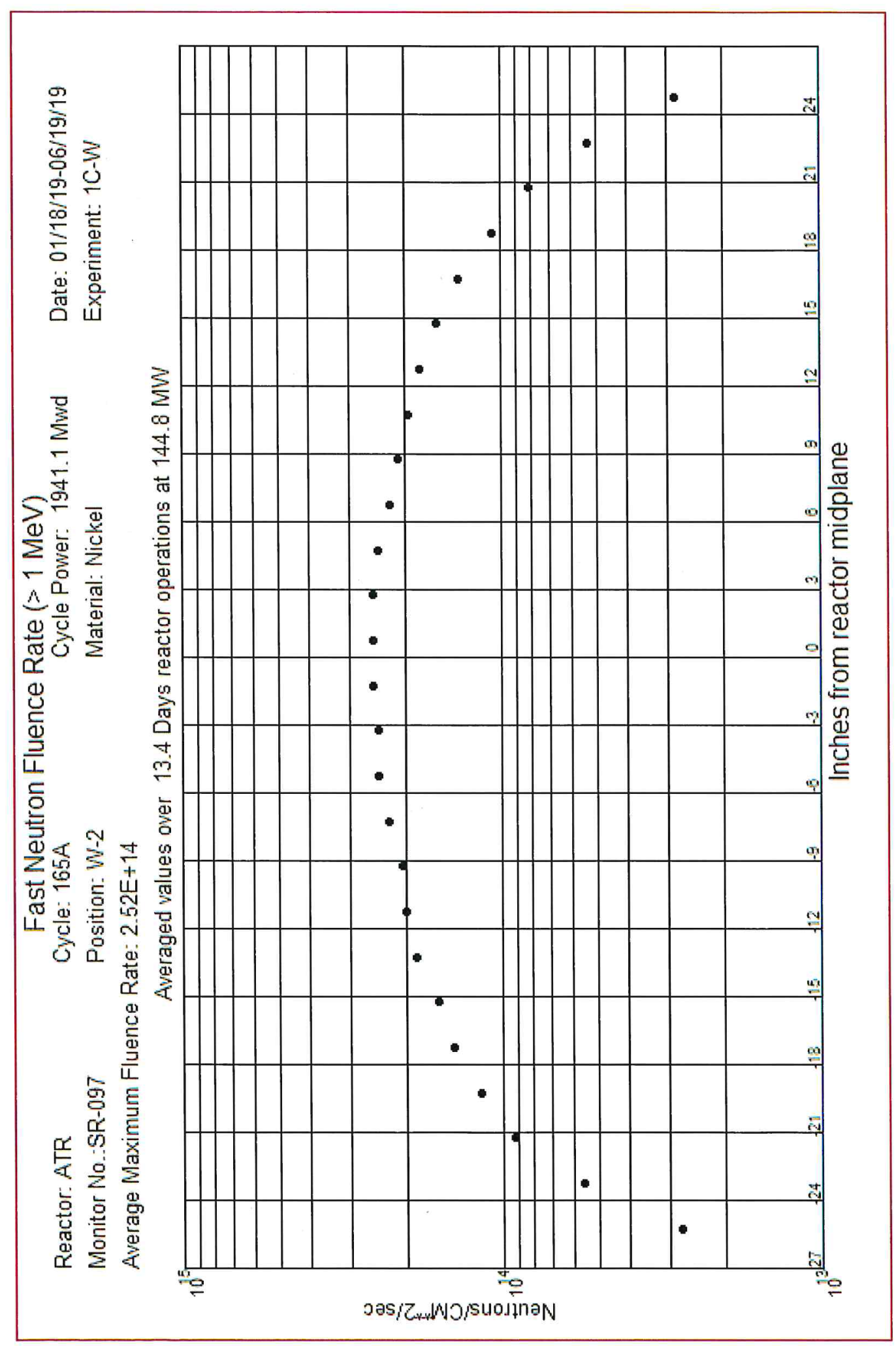




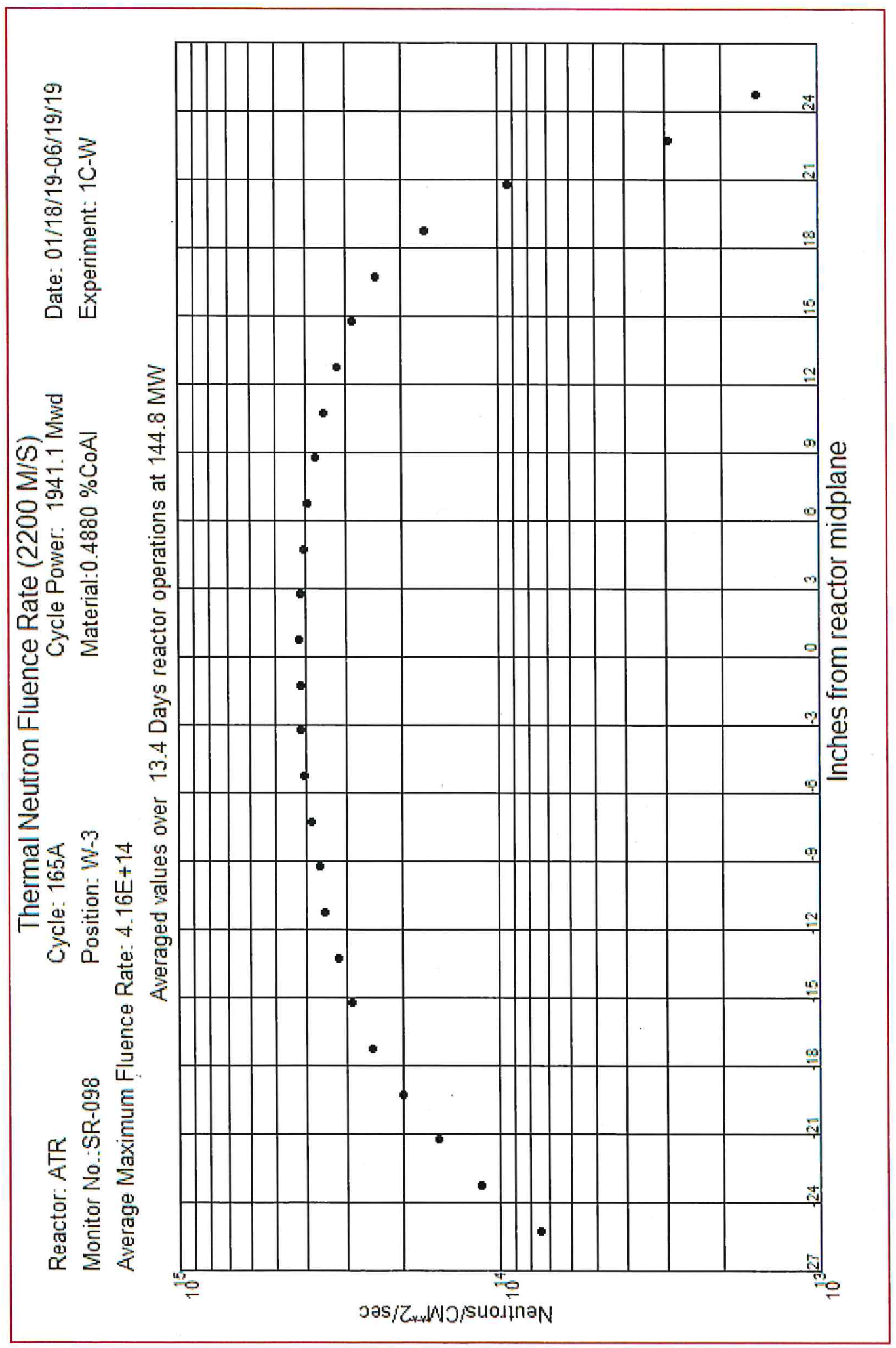




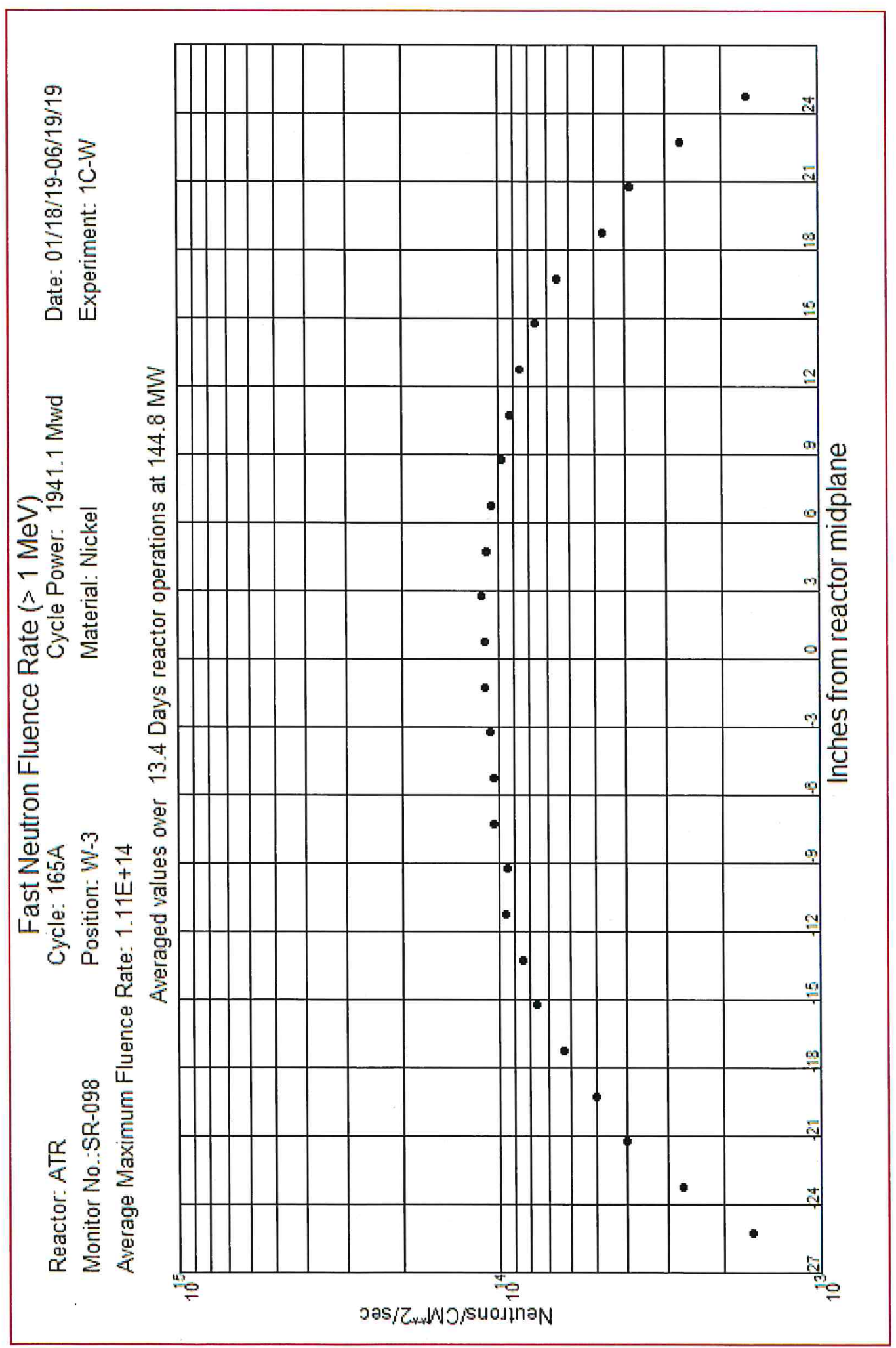




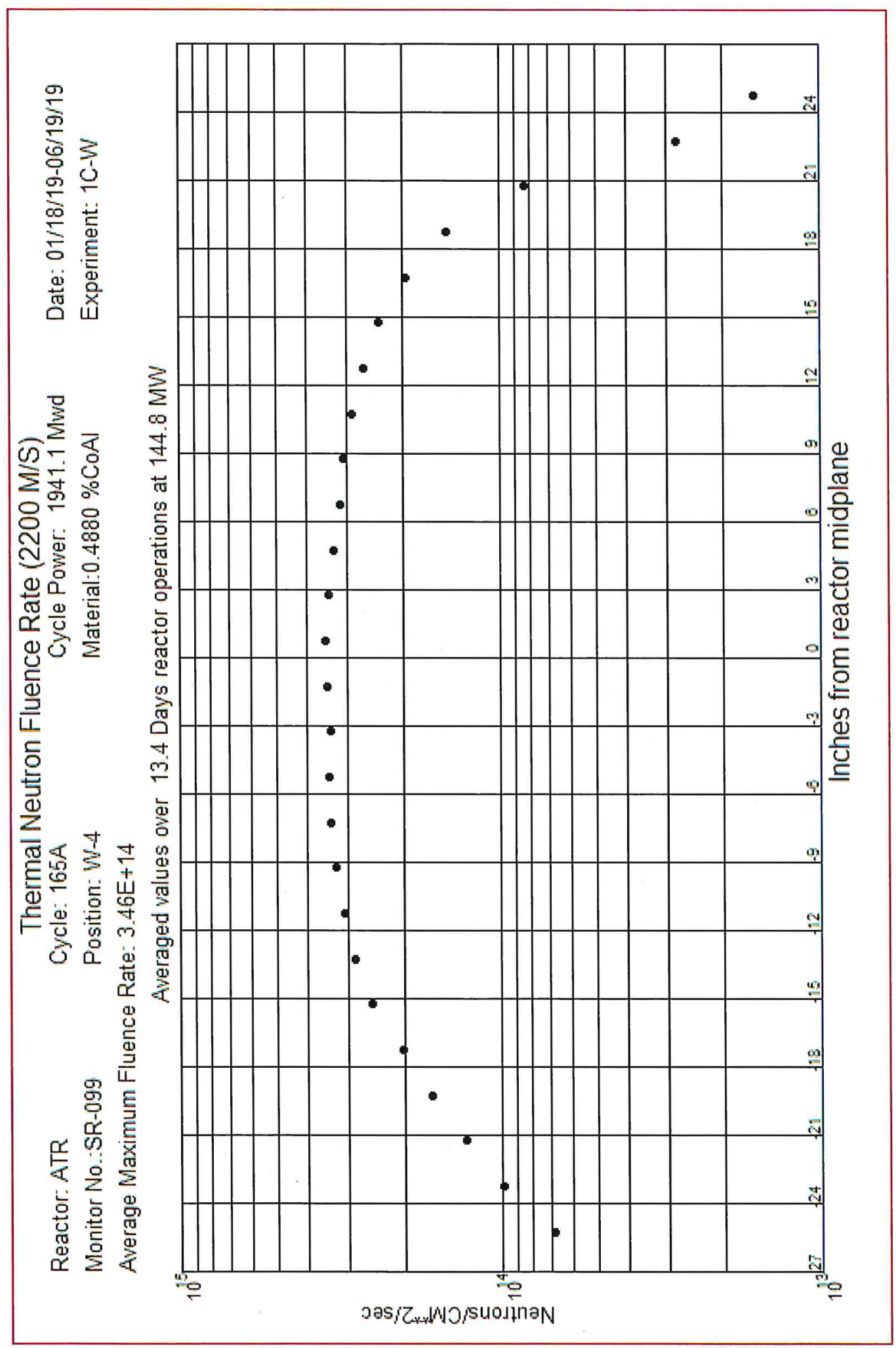




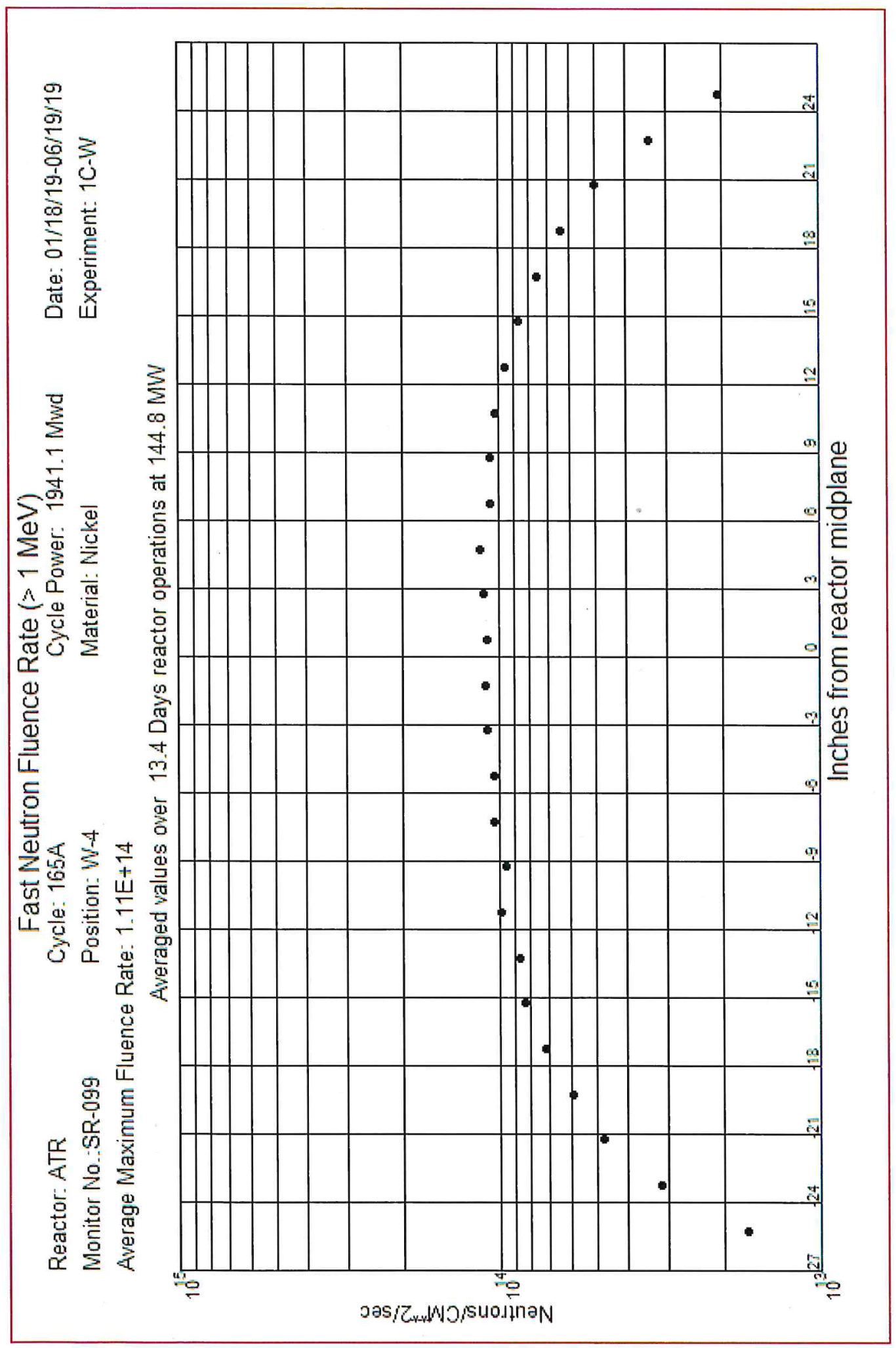

